
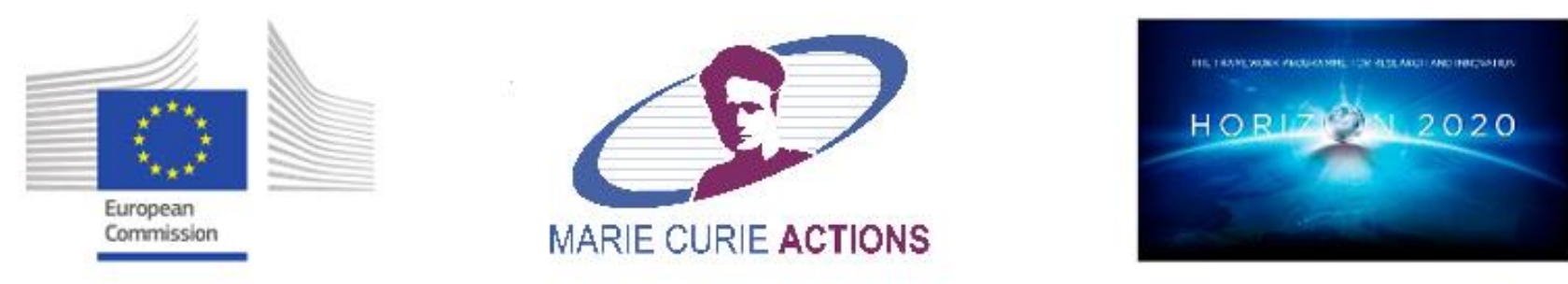

This project has received funding from the European Union's Horizon 2020 research and innovation programme under the Marie Skłodowska-Curie grant agreement No 645704 


\section{GENERALIZED QUALITY CONTROL PARAMETER FOR HETEROGENOUS RECYCLED CONCRETE AGGREGATES: A PILOT SCALE CASE STUDY}

\section{Caroline Santana Rangel}

Department of Civil Engineering, Federal University of Rio de Janeiro COPPE/UFRJ e-mail: carolrangel@ poli.ufrj.br

\section{Romildo Dias Toledo Filho}

Department of Civil Engineering, Federal University of Rio de Janeiro COPPE/UFRJ P.B. 68506, CEP 21941-972, Rio de Janeiro-RJ, Brazil.

e-mail: toledo@coc.ufrj.br

\section{Mayara Amario}

Department of Civil Engineering, Federal University of Rio de Janeiro COPPE/UFRJ e-mail: mayara_amario@poli.ufrj.br

\section{Marco Pepe}

Department of Civil Engineering, University of Salerno, Italy

TESIS srl, Fisciano (SA), Italy www.tesis-srl.eu

e-mail: mapepe@unisa.it / m.pepe@tesis-srl.eu

\section{Gabriela de Castro Polisseni}

Department of Civil Engineering, Federal University of Rio de Janeiro COPPE/UFRJ e-mail: gabriela.polisseni@gmail.com

\section{Gabriella Puente de Andrade}

Department of Civil Engineering, Federal University of Rio de Janeiro COPPE/UFRJ e-mail: puentedg@gmail.com

Corresponding author: toledo@coc.ufrj.br 


\section{ABSTRACT}

Although Recycled Concrete Aggregates, RCAs, derived from concrete waste, represent a potential sustainable solution for the structural concrete production, their heterogeneous composition is a feature that still prevents their large-scale use in the construction industry all around the world.

In order to find a possible existing relationship between the source of residues and the resulting RCAs characteristics, a pilot scale case study was carried out, in which approximately 20 tons of concrete waste, derived from different origins, were processed to obtain granulometric fractions from coarse aggregates to powders. The RCAs fractions obtained using a controlled processing procedure were then thoroughly characterized to establish quality control parameters that could lead to a classification of different types of recycled aggregate generated.

The results show that the source of concrete waste strongly influences the amount of each aggregate fraction produced during processing and aggregate properties were dependent on the waste origin. Despite this, the presented analysis demonstrated, that by evaluating a fundamental parameter such as the Attached Paste/Mortar within the RCAs, a generalized quality-control classification can be proposed for the industrial upscaling of RCAs characterization.

It is believed that such a classification could promote the integral and rational re-use of these secondary raw materials in different cement based products of the construction sector.

KEYWORDS: Construction and Demolition Waste, Recycled Concrete Aggregates, Attached Mortar, Processing procedure, Pilot scale application. 


\section{INTRODUCTION}

In the last decades, the construction industry has been identified to be one of the industrial sector with the greater environmental impact (Braga et al., 2017) since building and demolition operations lead to a significant waste generation and, in addition, the production of construction materials represents one of the major consumer of natural resources and energy (Dahlbo et al., 2015). Worldwide, the volumes of generated construction and demolition waste (CDW) are increasing rapidly both in developed and developing countries,: e.g., annually, 871 million tons of CDW are produced in Europe (Waste Statistics, 2017), while 534 million tons are generated in the United States (EPA, 2017) and the annual CDW production in China exceeds 1.5 billion tons (Huang et al., 2018). This is mainly due to the changes required for modern cities and infrastructures construction and re-construction (Zhang et al., 2018) but also because many existing residential and non-residential buildings need to be retrofitted both from the structural (e.g., due to the durability-related issues regarding reinforced concrete structures) and energy-efficient point of view (Ma et al., 2012). In addition, natural disasters (e.g., earthquakes), concentrated in vulnerable regions, lead to the exigence of re-constructing entire villages and cities (Faleschini et al., 2017).

CDWs are usually randomly dumped or discarded in landfills, but this proves not be a solution - in fact, it aggravates the environmental problem on the long-term. In this context, waste recycling is an alternative with great potentials to minimize the environmental impact generated by both the extraction of natural resources and the inadequate disposal of waste (Silva et al., 2016). The contribution of CDW recycling is superior compared to traditional treatment methods for waste management (Wijayasundara et al, 2018). Several studies have shown, that by comparing three different scenarios (recycling, incineration and landfill disposal) in terms of global warming potential, the most environmentally friendly way to treat CDW is recycling, followed by incineration and then by landfill disposal (Ortiz et al., 2010). In fact, there are many advantages of waste recycling: conservation of environmental preservation areas, increase of the lifetime of landfills, reduction of 
pollution and energy costs, reduction of the consumption of natural resources and reuse of waste that would be disposed of in landfills (Ulubeyli et al., 2017). It is worth mentioning that, certainly, more benefits could be obtained from the actual prevention of CDW, which is also a waste management option, rather than on the recycling of CDW itself. Despite this, the CDW recycling practices are worldwide becoming more and more necessary with several countries establishing goals with this objective. For example, the European Community (EC) committee states that at least $70 \%$ of all CDWs must be prepared for reuse and recycling by 2020 (EC, 2008).

Nevertheless, the actual average CDW recycling rate in China is only about 5\% (Huang et al., 2018) compared to the CDW recycling and reuse rate reaching $70-95 \%$ in some industrialized countries, including the United States, Denmark, South Korea, Singapore, Japan and Germany (Pepe, 2015). In Portugal, about $76 \%$ of all CDWs are disposed in landfills, $11 \%$ are reused, $4 \%$ are incinerated, and only 9\% are actually recycled (Coelho \& de Brito, 2013). This is a small amount when compared with other European countries (e.g., UK with 52\%, the Netherlands with 92\%, Belgium with 89\%, Austria with $48 \%$ and Denmark with $81 \%$ (Faella et al., 2016).

One of the main issues related to the promotion and the diffusion of recycling processes for $\mathrm{CDW}$ is the lack of confidence of consumers and builders regarding the quality of the generated aggregates due to the heterogeneity of the recycled waste employed. The construction and demolition waste can be classified in different types and one of the most used is in relation to the characteristics of the original source: the residue can come from construction, demolition, renovation of buildings and natural disasters or those cause by human hand. In general, CDW is a mixed residue, but the degree of heterogeneity depends mainly on its origin (Al-Bayati et al., 2016). Nevertheless, despite the very heterogeneous composition of the CDW (Paranhos et al., 2016), there is a high potential for its recycling in the form of aggregate, since around $40 \%$ to $85 \%$ of these materials are composed of concrete, mortar, rocks and ceramic materials (ES, 2017). Various studies have shown that the amount of inert materials in relation to the total amount of CDW represents approximately $58 \%$ in Portugal (Pereira et al., 2004), 67\% in Norway (Bergsdal et al., 2007) and 85\% in Italy (Costa \& Ursella, 
2003) and Spain (Reixach et al., 2000). Within these sources, in the last decades, many studies demonstrated the potential of using fine and coarse recycled concrete aggregate (i.e., presenting at least $90 \%$ by mass of Portland cement-based fragments and rocks), replacing "ordinary" particles derived from a natural source, for normal and high-strength structural concrete production (Amario et al., 2017). This highlights the potential of the CDW recycled process, even though most of these studies have been performed at a laboratory scale without demonstrating the real possibility of upscaling the RCAs production at an industrial level.

RCA particles can be obtained from different types of original concretes (e.g., demolition of existing concrete frames and elements or residues of fresh concrete from ready mix companies), which are commonly more porous, rougher and more irregular than the corresponding natural aggregates due to the presence of the attached mortar within the particles' composition (Pepe et al., 2016). Thus, the RCAs are characterized by considerably higher water absorption and lower specific mass than natural aggregates (Koenders et al., 2014). Consequently, the properties of the RCAs are directly related to the characteristics and quantity of this mortar adhered to the grains.

In view of these peculiarities, a protocol processing procedure, aimed also at identifying key quality-control parameters for the RCAs' characterization, should be defined in order to promote the worldwide production of high-performance products including those secondary raw materials. In this context, a case study was carried out where approximately 6-7 tons of concrete waste from 3 different concrete-waste sources (for a total amount of approximately 20 tons), were processed, simulating a recycling process in an industrial pilot plant. In fact, the key innovative aspect of the present study is that it aims at identifying and defining a quality management of the concrete-waste derived from different sources in order to promote their recycling for "high-end" application and, at the same time, demonstrate a pilot scale application for their usage on large scale in the market.

The first concrete debris was produced in the laboratory with the purpose of simulating concrete construction waste: with early age, with dosage and controlled properties and without contamination. The second consists of a fresh concrete residue from the washing of remaining material adhered to 
the wall of concrete-mixer trucks from a concrete production plant: with unknown dosage and properties, recent age and high addition of water to the mixture (high w/c ratio). The third consists of waste obtained from a concrete recycling plant, that is, it is demolition waste with a mixture of different types of concrete: with unknown dosage and properties and advanced age. For each residue, RCAs of four granulometric size fractions were produced: coarse 1, coarse 0 , sand and powder. The quantities produced from each fraction were measured for all three concrete-waste sources, in order to quantify the proportion of each aggregate and the losses involved in the process. The RCAs fractions were then thoroughly characterized in order to establish quality control parameters that could lead to the classification of different types of recycled aggregate generated. 


\section{MATERIALS AND METHODS}

\subsection{Concrete-waste sources}

Three different concrete-waste sources were considered for producing the RCAs: (i) the debris derived from concrete produced in the laboratory, named "laboratory produced" waste ( L-waste) (see Fig. 1a); (ii) the debris derived from a ready-mix concrete plant production, named "concrete plant" waste (C-waste) (see Fig. 1b); and (iii) debris obtained from a concrete recycling plant, named “demolition" waste (D-waste) (see Fig. 1c). From each source, approximately 7 tons of debris were derived. One of the main objectives of the present study is to propose a "processing path" to be followed and possibly identifying key parameters for describing the characteristics of RCAs derived from both controlled recycled material (i.e., RCAs derived from $L$-waste) with the uncontrolled ones (i.e., RCAs derived from general Construction and Demolition waste).

\subsubsection{Laboratory-produced waste}

The $L$-waste was derived from the crushing process of C30 concrete samples produced in the laboratory under controlled condition. The raw material characteristics, as well as the mixture proportioning, used for the "original" concrete, were completely known. As a result, the obtained debris was free from contaminations and/or impurities. It can be claimed that this kind of debris represents the waste derived from new concrete construction.

Specifically, the original concrete (see Fig. 1a) was produced with natural sand, natural coarse aggregates (maximum diameter of $9.5 \mathrm{~mm}$ ), high initial strength Portland cement (CPV-ARI in accordance with the NBR5733 (1991)) and polycarboxilate superplasticizer. The choice of using aggregates with a maximum diameter of $9.5 \mathrm{~mm}$ had the objective of producing the resulting RCAs with a high amount of attached mortar (AM), since this study aims to better understand how the AM is related to the properties of the corresponding RCAs. The water-to-cement ratio was 0.60 and the cement was $353 \mathrm{~kg} / \mathrm{m}^{3}$. The mixture was produced in a planetary mixer and cast in cylindrical molds 
( $\mathrm{d}=150 \mathrm{~mm}$ and $\mathrm{h}=300 \mathrm{~mm}$ ). The demolding of the specimens was performed after 24 hours, followed by curing in a moist chamber for 28 days. Then, the specimens were subjected to rupture in order to obtain fragments for the crushing stage. Compressive tests indicated that the average strength and the elastic modulus were $33 \mathrm{MPa}$ and $22 \mathrm{GPa}$, respectively, after 28 days of curing.

\subsubsection{Concrete plant waste}

The $C$-waste was supplied by a ready-mix concrete plant company (Supermix), located in Rio de Janeiro (Brazil). This material is composed of concrete waste that remains in the mixer trucks after the delivery of the concrete to the construction site. The strength class was unknown and the waterto-cement ratio of the waste was higher than the one of the delivered concrete as some water is normally used to clean the internal walls of the mixer. The authors recognize that there is already a current practice in ready-mix concrete plants to wash the returned concrete separating the gray water from the aggregates that can be already used in a new concrete batch. Despite this, it was decided to process this waste with the main objective of analyzing the properties of RCAs derived from very different range of properties.

The waste was delivered in the fresh state in mixer truck and was allowed to cure with a wet blanket during 28 days, avoiding the contamination of this material, before it was processed for RCAs production. The waste was processed for obtaining a RCAs characterized by high porosity, low abrasion resistance, high water absorption and low specific gravity, in order to extend the range of application of the formulation proposed in the next sections. Fig. 1b shows the $C$-waste in the hardened state, as employed in the present study.

\subsubsection{Demolition Waste}

The D-waste (see Fig. 1c) was supplied by a recycling plant company (Foccus - Gerenciamento de Resíduos), located in São Paulo, Brazil. This material is composed of debris of concrete elements derived from several demolition sites, and consequently, its composition is unknown as well as its "age" undefined. 


\subsection{From waste to recycled aggregates: the processing procedures}

The debris of $L-, C$ - and $D$ - waste was processed in the following three stages: crushing, grain-size classification by mechanical sieving and homogenization.

First of all, the debris of concrete waste was fragmented using a jaw crusher. Its mandibles opening was set to produce coarse aggregates of a maximum diameter of $19 \mathrm{~mm}$ (see Fig. 1d). As a result of the crushing process, besides the RCAs coarse fraction (see Fig. 1e), fine particles $(\mathrm{d}<4.75$ $\mathrm{mm}$ ) were also obtained (see Fig. 1f). The two granular classes of aggregates were then stored in bags and conducted to the sieving stage.

Then, the grain-size classification was carried out in two stages: (i) industrial mechanical sieving, dividing the coarse particles into two granulometric sizes (" $\mathrm{Cl}$ " with $19 \mathrm{~mm}>\mathrm{d}>9.5 \mathrm{~mm}$ and "CO" with $9.5 \mathrm{~mm}>\mathrm{d}>4.75 \mathrm{~mm}$ ) and (ii) laboratory mechanical sieving, employed for the fine particles classification (sand " $S$ " with $4.75 \mathrm{~mm}>\mathrm{d}>150 \mu \mathrm{m}$ and powder " $P$ " with $\mathrm{d}<150 \mu \mathrm{m}$ ). Fig. $\mathbf{1 g}$ to Fig. 1i illustrate the industrial mechanical sieving phase in which, first of all, the stored bags (containing the coarse particles resulting from the previous crushing stage) fed the sieve belt (Fig. 1g) passing through sieving screens (Fig. 1h) until the classified RCAs (Fig. 1i) obtained. It was observed that, although the jaw crusher was set to obtain a maximum nominal diameter equal to 19 $\mathrm{mm}$, a certain amount of particles was retained in the $19 \mathrm{~mm}$ mesh. A sieve shaker was used for the laboratory mechanical sieving for the RCAs fine particles classification., In order to prevent the dust being lost during sieving, a proof cover was employed. Further it was observed that for the coarse fraction (i.e., subjected to the industrial mechanical sieving) the powder loss was relatively low.

After the sieving stage, the classified RCAs were homogenized using the "cells process" (see Fig. 1j to Fig. 11). With this process, the RCAs were spread on a plastic sheet in different layers throughout the whole length of the sheet. Thus, the aggregates are homogenously distributed over the length of the sheet, and, starting from the middle section, layers of raw materials are subdivided in several sections called "cells" (Pepe et al., 2014). 
One of the objectives of the present study is to analyze the influence of the concrete waste source on the resulting amount generated for each RCAs class by maintaining the same processing stages. For this reason, at the end of the RCAs production process, each produced class was weighed in order to determine the obtained amount of coarse recycled aggregates, sand and powder.

\subsection{RCAs qualification}

With the objective of determining the quality of the coarse and sand classes of produced RCAs, as well as of three classes of ordinary reference natural aggregates (see Table 1), the following standard tests were performed: particle size distribution $(N B R 28,2003)$, particles density, water absorption capacity at 24 hours (NBR NM 30, 2001; NBR NM 52, 2009; NBR NM 53, 2009), shape index (NBR 7809, 2006), Los Angeles abrasion (NBR NM 51, 2001) and image analysis by SEM.

Then, as reported in the introduction section, a specific characterization for RCAs (e.g., the quantification of the AM content) was proposed by using non-conventional methods:

- Water absorption over time: based on the test method for determination of the total absorption (24 h) (NBR NM 53, 2009), the test was adapted to determine a curve of water absorption over time for each coarse aggregate. For this test, samples were used in the natural sun-dried condition. They were submerged in water for periods of $2,5,10,30$ and 60 minutes and 24 hours. When the sample was removed from the water, the surface was dried with an absorbent cloth to remove all visible water and the aggregate was weighed. The mass of absorbed water was calculated as the difference between the final and the initial mass. For fine aggregates, the curve of water absorption over time was determined by adapting the test method for the determination of the total absorption ( $24 \mathrm{~h})(N B R$ NM 52, 2009). First, the samples were dried at $60^{\circ} \mathrm{C}$ until reaching a constant mass value. Different samples of $150.0 \mathrm{~g}$ were submerged in water for periods of $1,2,3,4,5,6,7,8,9,10,15,30,60,120$, 240 and 360 minutes and 24 hours. When removed from the water, the sample was dried with a slight draft until there was no water between the grains. To identify this state of saturated aggregates with a dry surface, a truncated cone, smaller than the one specified by the standard, was designed with 
dimensions proportional to the original one. The truncated cone had to be fully filled with the sample and then the grains inside were compacted. When the truncated cone was removed and the compacted grains collapsed, the point of saturated grains without water between them was identified and the final mass was weighed. Also, in this case, the absorption is calculated by the difference between the final and initial mass;

- Attached mortar content by thermal shock: in order to quantify the attached mortar content of the coarse recycled aggregates, a thermal shock method was carried out, based on methods used in the literature (Pandurangan et al., 2016). The sample was dried at $60{ }^{\circ} \mathrm{C}$ until mass constancy, and weighed. The sample was placed in water at $5{ }^{\circ} \mathrm{C}$ for 10 minutes and then placed directly in a stove at $600{ }^{\circ} \mathrm{C}$ for two hours. Then, the material was again placed in water at $5{ }^{\circ} \mathrm{C}$ for 10 minutes. Soon after, the sample was rubbed into a cloth so that the mortar would crumble and separate from the original natural particle. The sample was sieved at $1.7 \mathrm{~mm}$ and washed to ensure that all the mortar was removed. Finally, the final sample was dried to mass constancy, and weighed. The AM content is the percentage obtained by the difference between the initial mass and the final mass;

- Attached paste content using acid: as there is no standard method in measuring old cement adhered to aggregates, this test was based on the literature (Braymand et al., 2017) and adapted for fine aggregates. The sample was dried at $60{ }^{\circ} \mathrm{C}$ until mass constancy and weighed, then immersed in a $30 \%$ hydrochloric acid solution for 24 hours. Then, the sample was placed on a $150 \mu \mathrm{m}$ sieve and washed with water to remove loose particles, and dried in an oven at a temperature of $60{ }^{\circ} \mathrm{C}$ until mass constancy to obtain the mass of the original aggregate. This experiment was also conducted for natural fine aggregate to ensure that it would not be damaged by the acid. Considering the size of the fine class, the "Thermal shock method" (performed on coarse particles) was not applied in the case of sand: this is because any eventual piece of attached mortar remaining on the natural sand grain, could result in an expressive experimental error.

Finally, analytical techniques, usually employed to characterize the physical-chemical performance of fines, were performed on the recycled powders: laser diffraction particle analysis, 
particle density with helium gas pycnometer, chemical composition, specific surface area (NBR 16372, 2015), XRD and thermogravimetric analysis. 


\section{RESULTS AND ANALYSIS}

\subsection{Quantity of each aggregate produced from each original source}

In order to highlight the semi-industrial scale of the proposed analysis, it is worth to mention that a total amount of around 20 tons of debris were processed: $6756 \mathrm{~kg}$ of L-waste, $6276 \mathrm{~kg}$ of $C$-waste and $6610 \mathrm{~kg}$ of D-waste. In Fig. 2 the percentage obtained for each class of RCAs produced in this study is illustrated. From the presented results it can be seen that the overall quantity of the coarse fraction was higher for the debris of $D$-waste (i.e., $68.2 \%$ ) followed by the $L$-waste (i.e., $46.6 \%$ ) and then the $C$-waste with a coarse percentage equal to $37.2 \%$. Then, focusing on the results obtained within the coarse fraction, it was observed that, since the crusher mandibles opening was set for obtaining a maximum nominal diameter equal to $19 \mathrm{~mm}$, the relative percentage of $C 1$ class aggregates was higher for the studied wastes $(85 \%, 75 \%$ and $70 \%$ for sources $D, L$ and $C$, respectively). This result is confirmed by the observation of the feed materials presented in Fig. 1c where debris of large dimension are predominant for $D$-waste. The difference in the percentages are due to the different sources of recycled concrete employed in this study. Depending on the original concrete composition/quality, the amount of coarse and fine fractions changes when keeping constant the processing procedure. The graphs presented herein, clearly emphasize this behavior. Another finding that stands out from Fig. 2 is the higher amount of the RCAs sand class that is produced from $C$-waste (i.e., $52.5 \%$ ), L-waste (i.e., $43.0 \%$ ) and then $D$-waste source where only $18.9 \%$ of fine aggregates were generated. Also in this case, this evidence is supported by the pictures shown in Fig. $\mathbf{1 b}$ where a predominant presence of small debris in $C$-waste source emerges. The higher amount of fine debris in $C$-waste is mainly due to its composition as it is obtained from remains of mixer trucks.

The percentage of recycled powder $(\mathrm{d}<150 \mu \mathrm{m})$ present in the overall amount of RCAs reached $3.9 \%, 3.1 \%$ and $2.0 \%$ for $L-, C$ - and $D$-waste, respectively. If only the fine fraction $(\mathrm{d}<4.75 \mathrm{~mm})$ is taken in account the relative percentages of powder are of the following values: $8.3 \%, 5.6 \%$ and $9.5 \%$ for $L-, C$ - and $D$-waste, respectively. 
The total amount of powder lost during the processing procedure was, in all cases, lower than $2 \%$ and, with the highest losses being observed for $C$-waste source. It must be empathized that the powder lost during the crushing stage was not recorded.

It is worth noting that, considering the three origin sources, the D-waste, presenting the higher percentage of coarse particles, is also the most representative residue of the construction industry. Finally, it can be concluded, that by keeping constant the processing procedure for transforming concrete debris into recycled aggregates, the amount produced for each class depends mainly on the original source and debris size. This evidence emphasizes the importance of a fundamental characterization for each obtained class in order to promote an integral and adequate re-use of these secondary raw materials.

\subsection{Recycled concrete aggregates properties and quality parameter control}

\subsubsection{Coarse aggregates}

The grading curves for coarse aggregates are shown in Fig. 3. For the coarser class of RCAs, the $R C A \_L \_C 1$ presents the higher percentage of particles with a nominal diameter ranging from $9.5 \mathrm{~mm}$ to $19 \mathrm{~mm}$ (i.e., around $80 \%$ ), while for both $R C A \_C \_C l$ and $R C A \_D \_C l$ this value does not exceed $75 \%$. In the case of the class $\mathrm{C} 0$, the percentage of particles with a diameter ranging between 4.75 mm and $9.5 \mathrm{~mm}$ is $80 \%$ for $R C A \_C \_C O$ and $95 \%$ for both $R C A \_L \_C O$ and $R C A \_D \_C O$. The fact that a certain amount of particles presents a nominal diameter lower than the designed one (i.e., $9.5 \mathrm{~mm}$ and $4.75 \mathrm{~mm}$ in the case of $\mathrm{C} 1$ and $\mathrm{C} 0$, respectively) might be due to transportation, handling operations and, mainly, due to the granulometric sieving tests (NBR 248, 2003). In fact, during the above mentioned procedures, friction between particles takes place breaking the pronounced particles' angularities, generating sand and coarse aggregates of lower nominal diameter. It is evident from the obtained results that this happened more for the $C$-waste source. This evidence will be later discussed based on the results obtained on the abrasion wear, attached mortar content and water absorption test results. 
The main results summarizing the properties of the produced RCAs are presented in Table 2. From the experimental results, it is not possible to define a clear trend between the oven dried particle density values, neither within each class nor the original source. For example, as the coarse particles of class $\mathrm{C} 1$ present higher values of particle density than class $\mathrm{C} 0$, for $C$ - and $D$-waste aggregates, an opposite trend is observed in the case of RCAs generated from L-waste source. Similar conclusions are achieved based on the results also for the water absorption capacity at 24 hours, Los Angeles abrasion and shape index.

These results confirm that, as also reported in the literature (Pepe et al., 2015), for a fundamental understanding of above mentioned aggregate properties, the RCAs characterization should be complemented with the evaluation of the attached mortar content.

This is well confirmed, for the coarse classes, by the graphs shown in Fig. 4. Specifically, a clear correlation can be detected between the AM content and both the water absorption capacity (Fig. 4a) and the oven dried particle density (Fig. 4b). These evidences are corroborated by the analysis proposed in Fig. 4a, in which the results achieved in this study, can be presented by the following equation recently proposed in the literature (Pepe et al., 2016):

$$
\mathrm{A}=\mathrm{A}_{\mathrm{NAT}} \cdot(1-\mathrm{AM})+\mathrm{A}_{\mathrm{AM}} \cdot \mathrm{AM}
$$

where $\mathrm{A}_{\mathrm{NAT}}$ (equal to $1 \%$ ) and $\mathrm{A}_{\mathrm{AM}}$ (equal to $15 \%$ ) represent the porosity of the two phases present in the RCAs: natural aggregates and attached mortar, respectively.

It is worth to highlight that the above correlations demonstrate that the evaluation of the AM content allowed a fundamental interpretation of key aggregate properties independently of the RCAs source and their granulometric class.

Since the AM content defines the values of both the particle density and the water absorption capacity of coarse RCAs, as presented in Fig. 5, a clear existing relationship can be identified between these two parameters. In the literature, an empirical relationship has been proposed by Silva et al. (2014) for describing this trend. However, as these two properties are physically correlated, a physically-based approach is proposed for its identification in the present study. 
In fact, by assuming that the oven dried density $\left(\gamma_{\mathrm{DRY}}\right)$ is a function of the total porosity of the particles $(p)$ and the specific density of the constituent material $\left(\gamma_{\mathrm{m}}\right)$ it results in

$$
\gamma_{\mathrm{DRY}}=(1-\mathrm{p}) \cdot \gamma_{\mathrm{m}} \Rightarrow \mathrm{p}=1-\frac{\gamma_{\mathrm{DRY}}}{\gamma_{\mathrm{m}}}
$$

In addition, assuming that the open porosity accessible by the water in 24 hours ( $\left.p_{\text {open }}\right)$ is equal to " $k$ " times the total porosity (p), the definition of the water absorption capacity is equal to

$$
\mathrm{A}=\frac{\mathrm{p}_{\text {open }} \cdot \gamma_{\text {water }}}{\gamma_{\mathrm{DRY}}}=\frac{\mathrm{k} \cdot \mathrm{p} \cdot \gamma_{\mathrm{water}}}{\gamma_{\mathrm{DRY}}}
$$

Then, replacing equation (2) in equation (3) the following expression can be obtained

$$
\gamma_{\mathrm{DRY}}=\gamma_{\mathrm{m}} \cdot \frac{1}{1+\frac{\mathrm{A}}{\mathrm{k}} \cdot \frac{\gamma_{\mathrm{m}}}{\gamma_{\text {water }}}}
$$

where the " $\mathrm{k}$ " parameter represents the amount of open porosity (i.e., accessible by the water during the water absorption capacity test) of the coarse particles and, this value has been calibrated to be between 0.9 and 0.70 (see Fig. 5). Based on the use of equation (4), in combination with the relationship proposed in Fig. 4a, a generalized coarse RCAs classification can be proposed:

- Class A: RCAs coarse particles characterized by A values ranging between $0 \%$ and $3 \%$ and an AM content lower than 10\%. Obviously, this class includes also natural aggregates;

- Class B: RCAs coarse particles characterized by A values ranging between $3 \%$ and $6 \%$ and an AM content between $10 \%$ and $35 \%$;

- Class C: RCAs coarse particles characterized by A values ranging between $6 \%$ and $9 \%$ and an AM content between $35 \%$ and $55 \%$;

- Class D: RCAs coarse particles A values above $9 \%$ and an AM content above $55 \%$.

The introduction of the above presented classification can be identified as a "quality-control" graph allowing to determine, with conventional parameters, the amount of AM independently from their original source. 
The Los Angeles (LA) abrasion is usually employed for the quality assessment of natural aggregates but when applied to RCAs it can generate some misunderstanding. In fact, looking at the results reported in Table 2 a general trend can be observed: by increasing the AM content the LA abrasion wear is more pronounced. However, a greater abrasion loss is registered for class C1 RCAs derived from $C$-waste (i.e., $58.5 \%$ ) in comparison with class C1 RCAs obtained from $L$-waste even though the latter presents almost the double amount of AM of the first. This indicates that the LA abrasion wear is governed by both the AM amount and its quality. Therefore, it strongly depends on the characteristic of the waste source. To confirm the above mentioned trend, a comprehensive analysis is made by plotting the obtained results with those available in the literature (see Fig. 6) (de Juan \& Gutiérrez, 2009). It is worth mentioning that the LA abrasion, for natural aggregates, is a function of the original rock mineralogy and, consequently, a high variability on its value is observed (22-60\%). The same magnitude of scatter is observed for the coarse RCAs containing different amounts of AM. This confirms the high dependence of the LA abrasion loss in relation with the AM quality (i.e., depending on the waste source characteristic). For these reasons, a generalized equation cannot be proposed since the AM quality is unknown by the users.

Then, regarding the shape index (see Table 2) it is worth to mention that, usually, it is related to several factors, such as the origin of the material, the resistance of the particle, the crushing process, and it is defined by the ratio between the largest grain length and its thickness. Therefore, the higher the value of the shape index the more lamellar the material is, and the smaller this value the more equidimensional the material is. The results reported in Table 2 show that the highest values were obtained for the natural aggregates although the shape index tends to increase by increasing the AM content in the case of RCAs. Since the shape index was evaluated at the end of the aggregates' processing production, the observed "rounder" shape of RCAs can be attributed to the breaking of the angularity occurring during the transportation, handling operations and the granulometric sieving tests. 
The percentage of the water absorption over time for coarse RCAs is shown in Fig. 7 whereas its initial rate (up to 2 minutes) is presented in Table 2 . The obtained results show that the particles with the higher amount of AM tend to present a high initial rate of water absorption. However, a higher value is obtained for $\mathrm{C} 1$ from $\mathrm{C}$-waste than for $\mathrm{C} 1 \mathrm{RCAs}$ from $L$-waste even though the latter presents a significant higher amount of AM. This means that, as observed for the LA abrasion results, the "quality" of the original AM plays a fundamental role on determining the water absorption in time evolution.

Fig. 8 presents the images obtained for the coarse particles analyzed in this study. The SEM images highlight the qualitative differences in the morphology, ITZs and the presence of AM for the sources and classes of particles. For example, it can be observed that the surface of the natural aggregates (see Fig. 8a and Fig. 8b for $N a t_{-} \mathrm{CO}$ and $\mathrm{Nat} C \mathrm{Cl}$, respectively) present similar texture and roughness. In the recycled aggregates, the presence of attached mortar was observed, as it was expected. This mortar has a lighter color and high porosity (see Fig. 8c to Fig. 8h). The transition zone between original natural aggregate and adhered mortar is also visible in all the recycled aggregates, presenting a well-defined region (see Fig. 8c to Fig. 8h).

\subsubsection{Fine aggregates}

The grading curves for the fine RCAs aggregates are shown in Fig. 3. Differently from what was observed for the coarse particles, in the case of the sand class, for all the sources more than $95 \%$ of particles present a nominal diameter in the specified range (i.e., $150 \mu \mathrm{m}<\mathrm{d}<4.75 \mathrm{~mm}$ ) indicating that the particles' breaking mechanisms above described for coarse aggregates do not occur for the sand grains. The grain-size distribution curves of the RCAs sand are very close to each other despite the different aggregates sources.

Then, the key physical properties, i.e., specific gravity, water absorption capacity and attached paste (AP) content, characterizing the sand class of RCAs are reported in Table 2. The results indicate that, as occurred for the coarse classes, also in the case of sand, the particle density as well as the 
water absorption capacity values can be determined as a function of the AP content and can be easily correlated within each other. This is confirmed by the graphs shown in Fig. 9 in which both the experimental data obtained herein as well as other data available in the literature are plotted (Evangelista et al., 2015). In the literature, an empirical relationship has been proposed by Evangelista et al (2015) for describing this trend. However, as these two properties are physically correlated in the present study, the above presented physically-based equation (4) has been calibrated for the case of sand particles. Specifically, in this case, the coefficient "k" has been assumed to be equal to 1. This means that in the case of fine particles, due to the higher specific surface in comparison with the corresponding coarse one, the water is able to reach $100 \%$ of the internal pores within the particles. Based on the proposed equation, the following sand classification for RCAs is proposed:

- Class A: RCAs sand characterized by A values ranging between $0 \%$ and $3 \%$ and an AP content lower than $10 \%$. Obviously, this class includes also natural aggregates;

- Class B: RCAs sand characterized by A values ranging between $3 \%$ and $6 \%$ and an AP content between $10 \%$ and $30 \%$;

- Class C: RCAs sand characterized by A values ranging between $6 \%$ and $9 \%$ and an AP content between $30 \%$ and $45 \%$;

- Class D: RCAs sand characterized by A values above $9 \%$ and an AP content above $45 \%$.

Also, for the RCAs sand class, the introduction of this classification can be identified as a "quality-control" graph allowing to determine, with conventional parameters, the amount of AP independently from their original source.

The kinetic of the water absorption for fine RCAs (see Fig. 7) highlights that, independently from the original source, the initial water absorption rate (up to 2 minutes) reaches values of around 34\% (see Table 2). This indicates that for the sand fraction, this parameter is less influenced by the original waste source than in the case of coarse particles. 
Finally, by analyzing the SEM images (see Fig. 10) the analysis earlier reported is confirmed. In fact, it is possible to notice that the $R C A \_L \_S$ (see Fig. 10b) grain distribution and shape are more similar to the Nat_S (see Fig. 10a) when compared to the other fine recycled aggregates. The $R C A \_C \_S$ (see Fig. 10c) contains clearly the greatest amount of fine particles, while $R C A \_D \_S$ (see Fig. 10d) has particles of varied sizes, confirming the data on the grading curve. As can also be seen on the SEM image, the quantity of attached paste is larger for the $R C A \_C \_S$ (see Fig. 10c), which can be explained by the fact that it has finer particles, because in the beneficiation process the paste breaks easily, compared to the grain of quartz, forming these smaller particles. On the other hand, the $R C A \_D \_S$ (see Fig. 10d) present the lowest amount of attached paste, quartz grains almost without paste can be easily seen on the image, and, finally, the $R C A \_L \_S$ (see Fig. 10b) has less than $R C A \_D \_S$ (see Fig. 10d) and more than $R C A \_C \_S$ (see Fig. 10c). Therefore, the quartz particles on $R C A \_C \_S$ that has the lower amount of paste, still seems to have more than the one attached to other aggregate grains. This way, the images confirm the results found on the attached paste test.

\subsubsection{Recycled powder}

The chemical composition of the recycled powders is shown in Table 3. The $R C A \_D \_P$ present a greater amount of silica (46\%) than the recycled powders derived from the other two sources. This result is confirmed by the analysis of the literature that emphasizes that if a concrete waste is used, the predominant phase is the $\mathrm{SiO}_{2}$ (Florea et al., 2014), and if a cement paste waste is employed as original source, the resulting recycled powder present more $\mathrm{CaO}$ than $\mathrm{SiO}_{2}$ (Gastaldi et al. 2015; Boudali et al., 2016). This indicates that the original $D$-waste source is composed of concrete mixtures produced with a greater amount of natural fine and coarse aggregates than the other two.

Fig. 11 summarizes the XRD analysis carried out on the used powders. All the recycled powders show that quartz is the major crystalline phase and a large amount of minerals peaks, like biotite, muscovite, microcline, are also present. The presence of portlandite, ettringite and calcite phases is also highlighted, indicating the presence of hydrated cement grains. In addition, the 
mineralogical composition also shows the presence of anhydrous cement compounds, such as $\mathrm{C}_{3} \mathrm{~S}$ and $\mathrm{C}_{2} \mathrm{~S}$, although in smaller quantities. The XRD analysis then demonstrates that the recycled powders are mainly composed of quartz (sand and crushed grit), hydrated cement and a small amount of anhydrous cement. Unfortunately, it is not possible to directly quantify the overall amount of each compound present in each recycled powder due to the presence of several types of minerals that may present different crystalline structures.

Fig. 12 presents the Thermogravimetric analysis (TGA), derivative thermo-gravimetric (DTG) and differential scanning calorimetry (DSC) curves for the studied powders. Four main peaks can be identified in the curves as described below:

- the peak 1 in DTG, between 35 and $230^{\circ} \mathrm{C}$, is referring to the dehydration of torbemorite $(\mathrm{C}$ S-H), decomposition of ettringite and gypsum;

- the peak 2 in DTG, between 380 and $460{ }^{\circ} \mathrm{C}$, corresponds to dihydroxylation of portlandite $(\mathrm{CH})$;

- the peak 3 in DSC curves for recycled powders, as found in the literature, shows a structural change of the quartz at $570{ }^{\circ} \mathrm{C}$.

- the peak 4 in DTG, between $600^{\circ} \mathrm{C}$ and $800^{\circ} \mathrm{C}$, indicating the decarbonation of calcium carbonate;

Based on the above measurements, it was possible to quantify the amount of quartz present in the recycled powders calculating the peak area (3). According to Sheffield (1994), the enthalpy at the alpha-beta pure quartz transition is $1.57 \mathrm{cal} / \mathrm{g}$. Thereby, the percentage of quartz is $17.25 \%, 14.09 \%$, and $6.64 \%$ for $R C A \_D \_\mathrm{P}, R C A \_L \_P$ and $R C A \_C \_P$, respectively. This confirms the higher presence of quartz in the $R C A \_D \_P$.

All the produced recycled powders showed the presence of tobermorite, ettringite, portlandite and calcium carbonate. Specifically, in terms of percentage content calculated in each initial mass basis, for the $R C A \_D \_P$ and $R C A \_C \_P$, the peaks 1 and 2 showed a lower content of combined water for C-S-H and ettringite (i.e., $1.68 \%$ and $3.37 \%$, respectively) and for portlandite (i.e., $0.38 \%$ and 
$0.29 \%$, respectively), comparing with $R C A \_L \_P$, which has $4.07 \%$ (for peak 1 ) and $1.55 \%$ (for peak 2).

The higher peak 4 for $R C A \_C \_P$ (i.e., 9.01\%) and $R C A \_D \_P($ i.e., $5.63 \%)$ that may be due to the presence of carbonated material (filler or aggregates) which increase the amount of $\mathrm{CaCO}_{3}$ in those powders, while $R C A \_L \_P$ presents lower content of $\mathrm{CO}_{2}$ (i.e., $4.47 \%$ ).

Regarding the physical properties of the powders, the particle size distribution of the studied materials is presented in Fig. 3. The results indicate that by utilizing the same processing procedures, the resulting recycled powders present a similar granulometric distribution independently from the original waste source. As a matter of the fact, the $\mathrm{D}_{50}$ (mean particle size) is $62.79 \mu \mathrm{m}, 62.97 \mu \mathrm{m}$ and $70.05 \mu \mathrm{m}$ for the $R C A \_L \_P, R C A \_D \_P$ and $R C A \_C \_P$, respectively. The diameter $D_{10}$ is about 8.90 $\mu \mathrm{m}, 10.20 \mu \mathrm{m}$ and $8.69 \mu \mathrm{m}$ whereas $\mathrm{D}_{90}$ is about $160.95 \mu \mathrm{m}, 157.20 \mu \mathrm{m}$ and $167.64 \mu \mathrm{m}$, for recycled powders derived from $L-, C$ - and $D$-waste sources, respectively. This finding is confirmed by the results of Schoon et al. (2015) who also studied recycled powders from CDW.

Despite the similar size particle distribution, the Blaine specific surface area was different for the powders derived from the different sources considered in the present study. In fact, while for $R C A \_L \_P$ and $R C A \_D \_P$ a similar Blaine specific surface area was obtained (i.e., $0.31 \mathrm{~m}^{2} / \mathrm{g}$ and 0.27 $\mathrm{m}^{2} / \mathrm{g}$, respectively), the $R C A \_C \_P$ presents a higher value equal to $0.46 \mathrm{~m}^{2} / \mathrm{g}$. This can be related to a greater surface porosity as the original $C$-waste had more water in their mix design due to the washing process of the ready mixer truck (see also Fig. 13). In addition, $R C A \_C \_P$ have the lower particle density $\left(2480 \mathrm{~kg} / \mathrm{m}^{3}\right)$ as compared with $R C A \_L \_P\left(\right.$ was $\left.2570 \mathrm{~kg} / \mathrm{m}^{3}\right)$ and $R C A \_D \_P(2630$ $\mathrm{kg} / \mathrm{m}^{3}$ ) that also reinforced that they are slightly more porous than the other two powders. It is worth to mention that the $R C A \_C \_P$ has a lower silica content than the other two powders, corroborating the higher specific surface results, since, as it is well known, the hydrated products generally present a higher specific surface in comparison with inert quartz (Shui et al., 2008).

Differently of what was established for the fine and coarse RACs particles, due to the complexity of the powder composition, it was not possible to identify a unique quality control 
parameter for their classification. A combination of techniques will be needed to characterize the powders depending on the desired end use. 


\section{CONCLUSIONS}

In this paper a pilot scale case study is reported in which approximately 20 tons of concrete waste, derived from different origins, were processed. Then a fundamental characterization on the resulting RCAs was performed with the aim of identifying quality-control parameters for their classification.

In accordance with the results obtained herein, the following conclusions can be drawn for the used processing procedures:

- The amount produced for each fraction mainly depends on the original source "quality", if the processing procedure for transforming the concrete debris into recycled aggregates is kept constant (and set in order to obtain a maximum nominal diameter of $19 \mathrm{~mm}$ ). As a matter of fact, from the $L$ waste source around $55 \%$ and $35 \%$ were obtained for coarse and fine aggregates, respectively; on the other hand, the debris derived from the residues of the ready-mix company (i.e., source " $C$ ") generated a higher amount of sand (more than 50\%) and a lower amount of coarse aggregates (i.e., $36 \%$ ). Conversely, from the demolition waste (source " $D$ ”) a significantly higher amount of coarse particles is obtained (more than 65\%) and only $18 \%$ of sand is generated;

- in all the cases, during the beneficiation process, just a low amount is considered as "loss" (i.e., lower than $2 \%$ ) and the main portion is composed of coarse aggregates and sand (more than 90\%). This gives an estimated overall amount of aggregates that could be re-used, for instance, for new concrete production by replacing the ordinary natural aggregates;

- the aggregates' properties, mainly, depend on the original concretes' characteristics. this leads to a higher heterogeneity on the RCAs' performance depending on the quality of the original source. For instance, the water absorption capacity ranges from $0.5 \%$ to $12 \%$, the shape index from 3.1 to 1.9 and the abrasion wear from $36 \%$ to $65 \%$;

- despite this, the identification of a fundamental parameter (the amount of the Attached Paste/Mortar within the RCAs that in our study ranged between 20\% and 70\%) can "overcome" the high heterogeneity of the recycled aggregates; 
- in fact, the analysis proposed herein highlights that the key properties of the recycled particles are directly related to it: the particles characterized by the highest amount of Attached Paste/Mortar also present the highest water absorption capacity and the lowest density that can be defined as a quality-control parameter;

- consequently, the identification the Attached Paste/Mortar characterizing RCAs leads toward a rational and simplified approach for the industrial upscaling of the RCAs production and characterization by proposing a simplified classification for both coarse and fine RCAs;

- the analysis proposed for the recycled powders highlights that they are composed of different phases: sand, crushed grit, hardened cement and a little part of anhydrous cement. Despite this, due to their complexity, it is not easy to identify a unique quality-control parameter for their classification. 


\section{ACKNOWLEDGEMENTS}

The present study is part of the activities carried out by the authors within the "SUPERCONCRETE" Project (www.superconcrete-h2020.unisa.it) funded by the European Union's Horizon 2020 Research and Innovation Programme under Grant Agreement No 645704 (H2020-MSCA-RISE-2014).

Moreover, the authors would like to thank Prof. Enzo Martinelli (Department of Civil Engineering, University of Salerno, Italy) for the fruitful discussions and his contribution on the analysis of the results related to the RCAs classification based on the physically-based approach proposed in this study. 


\section{REFERENCES}

Al-Bayati, H.K.A., Das, P.K., Tighe, S.L., Baaj, H., 2016. Evaluation of various treatment methods for enhancing the physical and morphological properties of coarse recycled concrete aggregate. Constr. Build. Mater., 112, 284-298.

Amario, M., Rangel, C. S., Pepe, M., Toledo Filho, R.D., 2017. Optimization of normal and high strength recycled aggregate concrete mixtures by using packing model. Cem. Concr. Compos., 84, 83-92.

Bergsdal, H., Bohne, R. A., \& Brattebø, H., 2007. Projection of construction and demolition waste in Norway. Journal of Industrial Ecology, 11(3), 27-39.

Boudali, S., Kerdal, D. E., Ayed, K., Abdulsalam, B., \& Soliman, A. M. (2016). Performance of selfcompacting concrete incorporating recycled concrete fines and aggregate exposed to sulphate attack. Constr. Build. Mater., 124, 705-713.

Braga, A.M., Silvestre, J.D., de Brito, J., 2017. Compared environmental and economic impact from cradle to gate of concrete with natural and recycled coarse aggregates. J. Clean. Prod., 162, 529543.

Braymand, S., Roux, S., Fares, H., Déodonne, K., Feugeas, F., 2017. Separation and quantification of attached mortar in recycled concrete aggregates. Waste Biomass Valorization, 8, 1393-1407.

Coelho, A., de Brito, J., 2013. Economic viability analysis of a construction and demolition waste recycling plant in Portugal-part I: location, materials, technology and economic analysis. J. Clean. Prod., 39, 338-352.

Costa, U., Ursella, P., 2003. Construction and demolition waste recycling in Italy. In International Conference on The Environmental and Technical Implications of Construction, 5, 231-239.

Dahlbo, H., Bachér, J., Lähtinen, K., Jouttijärvi, T., Suoheimo, P., Mattila, T., Sironen, S., Myllymaa, T., Saramäki, K., 2015. Construction and demolition waste management-a holistic evaluation of environmental performance. J. Clean. Prod., 107, 333-341.

de Juan, M.S., Gutiérrez, P.A., 2009. Study on the influence of attached mortar content on the properties of recycled concrete aggregate. Constr. Build. Mater., 23(2), 872-877.

EC, 2008. Directive 2008/98/CE of the European Parliament and of the Council of 19 November 2008 on waste and repealing certain Directives. Official Journal of the European Union.

EPA, 2017. Advancing Sustainable Materials Management: Facts and Figures Report", Environmental Protection Agency, www.epa.gov/smm/advancing-sustainable-materialsmanagement-facts-and-figures-report (Accessed 14.11.17).

ES, 2017. Generation and Treatment of Waste, Eurostat Statistics Explained www.ec.europa.eu/eurostat (Accessed 14.11.17).

Evangelista, L., Guedes, M., de Brito, J., Ferro, A.C., Pereira, M.F., 2015. Physical, chemical and mineralogical properties of fine recycled aggregates made from concrete waste. Constr. Build. Mater., 86, 178-188. 
Faella, C., Lima, C., Martinelli, E., Pepe, M., Realfonzo, R., 2016. Mechanical and durability performance of sustainable structural concretes: an experimental study. Cem. Concr. Compos., 71, $85-96$.

Faleschini, F., Zanini, M. A., Hofer, L., Zampieri, P., Pellegrino, C., 2017. Sustainable management of demolition waste in post-quake recovery processes: The Italian experience. Int J Disaster Risk Reduct, 24, 172-182.

Florea, M. V. A., Ning, Z., Brouwers, H. J. H. 2014. Activation of liberated concrete fines and their application in mortars. Constr. Build. Mater., 50, 1-12.

Gastaldi, D., Canonico, F., Capelli, L., Buzzi, L., Boccaleri, E., Irico, S. 2015. An investigation on the recycling of hydrated cement from concrete demolition waste. Cem. Concr. Compos., 61, 2935 .

Huang, B., Wang, X., Kua, H., Geng, Y., Bleischwitz, R., Ren, J., 2018. Construction and demolition waste management in China through the 3R principle. Resour. Conserv. Recycl., 129, 36-44.

Koenders, E.A., Pepe, M., Martinelli, E., 2014. Compressive strength and hydration processes of concrete with recycled aggregates. Cem Concr Res., 56, 203-212.

Ma, Z., Cooper, P., Daly, D., \& Ledo, L. (2012). Existing building retrofits: Methodology and stateof-the-art. Energ. Buildings, 55, 889-902.

NBR 16372, 2015. Portland cement and other powders materials - Determination of fineness by the air permeability method (Blaine method). ABNT.

NBR 248, 2003. Aggregates - Sieve analysis of fine and coarse aggregates. ABNT.

NBR 5733, 1991. High early strength Portland cement - Specification. Associação Brasileira de Normas Técnicas.

NBR 7809, 2006. Coarse aggregate - Determination of shape index by the caliper - Method of test. ABNT.

NBR NM 30, 2001. Fine aggregate - Test method for water absorption. ABNT.

NBR NM 51, 2001. Small-size coarse aggregate - Test method for resistance to degradation by Los Angeles machine. ABNT.

NBR NM 52, 2009. Fine aggregate - Determination of the bulk specific gravity and apparent specific gravity. ABNT.

NBR NM 53, 2009. Coarse aggregate - Determination of the bulk specific gravity, apparent specific gravity and water absorption. ABNT.

Ortiz, O., Pasqualino, J. C., Castells, F., 2010. Environmental performance of construction waste: comparing three scenarios from a case study in Catalonia, Spain. Waste Manage., 30(4), 646-654.

Pandurangan, K., Dayanithy, A., Prakash, S., 2016. Influence of treatment methods on the bond strength of recycled aggregate concrete. Constr. Build. Mater., 120, 212-221. 
Paranhos, R. S., Cazacliu, B.G., Sampaio, C.H., Petter, C.O., Neto, R.O., Huchet, F., 2016. A sorting method to value recycled concrete. J. Clean. Prod., 112, 2249-2258.

Pepe, M., 2015. A conceptual model for designing recycled aggregate concrete for structural applications. Springer Theses, Springer.

Pepe, M., Toledo Filho, R. D., Koenders, E. A., Martinelli, E., 2016. A novel mix design methodology for Recycled Aggregate Concrete. Constr. Build. Mater., 122, 362-372

Pepe, M., Toledo Filho, R. D., Koenders, E. A., Martinelli, E., 2014. Alternative processing procedures for recycled aggregates in structural concrete. Constr. Build. Mater., 69, 124-132.

Pereira, L., Jalali, S., Aguiar, J., 2004. Construction and demolition waste management. In: Workshop Integrated Management Systems for Specific Waste Streams, Lisbon, Portugal.

Reixach, F., Barroso, J., Cusco, A., 2000. Waste Management Plan in Construction and Demolition Works. General Direction of the Environment, Institute of Construction Technology of Catalonia, Spain (in Spanish).

Schoon, J., De Buysser, K., Van Driessche, I., De Belie, N. 2015. Fines extracted from recycled concrete as alternative raw material for Portland cement clinker production. Cem. Concr. Compos., $58,70-80$.

Sheffield, G. S. (1994). Quantitative measurement of crystalline silica by thermal analysis. Anal. Chim. Acta, 286(1), 125-128.

Shui, Z., Xuan, D., Wan, H., Cao, B. 2008. Rehydration reactivity of recycled mortar from concrete waste experienced to thermal treatment. Constr. Build. Mater., 22(8), 1723-1729.

Silva, R.V., de Brito, J., Dhir, R.K., 2014. Properties and composition of recycled aggregates from construction and demolition waste suitable for concrete production. Constr. Build. Mater., 65, 201217.

Silva, R.V., de Brito, J., Dhir, R.K., 2016. Availability and processing of recycled aggregates within the construction and demolition supply chain: A review. J. Clean. Prod., 143, 598-614.

Ulubeyli, S., Kazaz, A., Arslan, V., 2017. Construction and demolition waste recycling plants revisited: management issues. Procedia Eng., 172, 1190-1197.

Waste Statistics, 2017. Eurostat Statistics Explained, www.ec.europa.eu, (Accessed 14.11.17).

Wijayasundara, M., Mendis, P., Crawford, R.H., 2018. Integrated assessment of the use of recycled concrete aggregate replacing natural aggregate in structural concrete. J. Clean. Prod., 174, 591604.

Zhang, X., Bayulken, B., Skitmore, M., Lu, W., \& Huisingh, D., 2018. Susainable urban transformations towards smarter, healthier cities: Theories, agendas and pathways. J. Clean. Prod., $173,1-10$. 


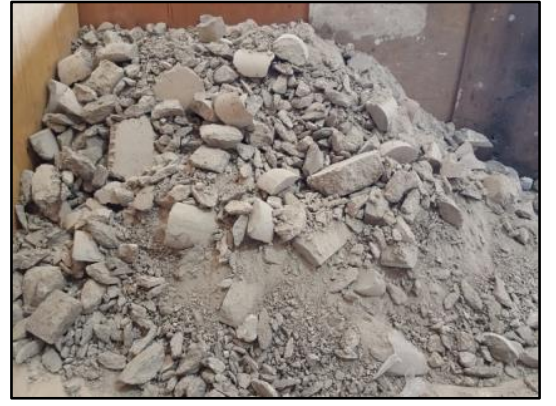

(a) L-waste

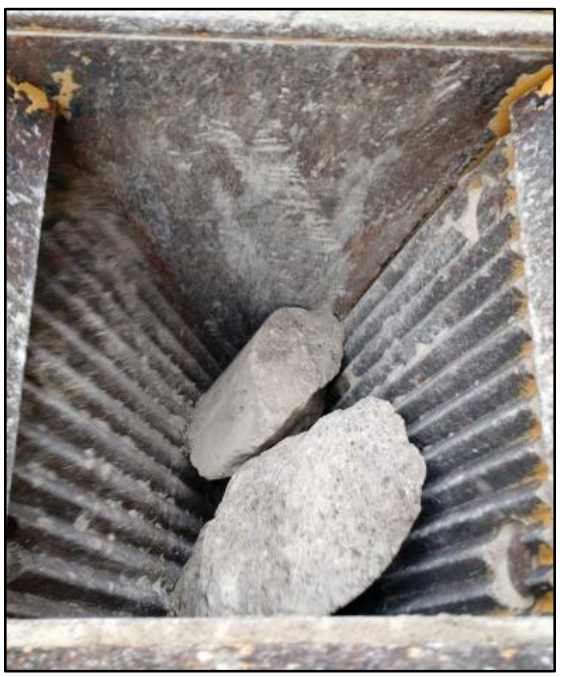

(d) feeding the debris waste

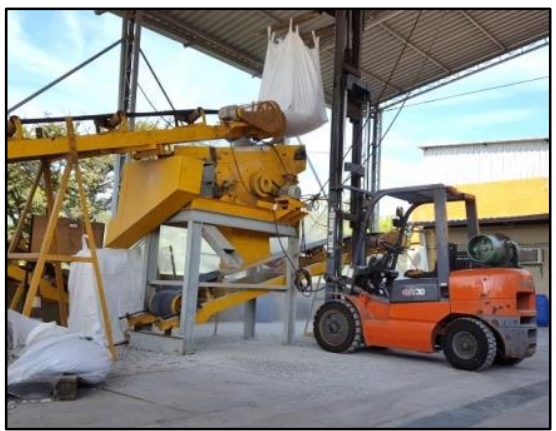

(g) feeding the coarse fraction

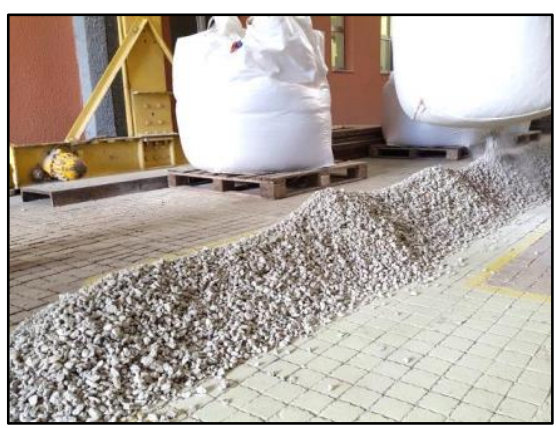

(j) RCAs pile

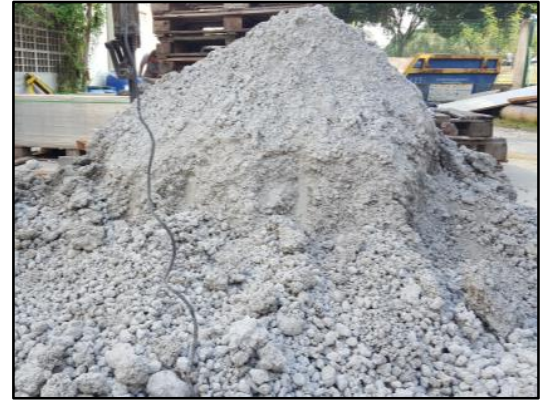

(b) C-waste

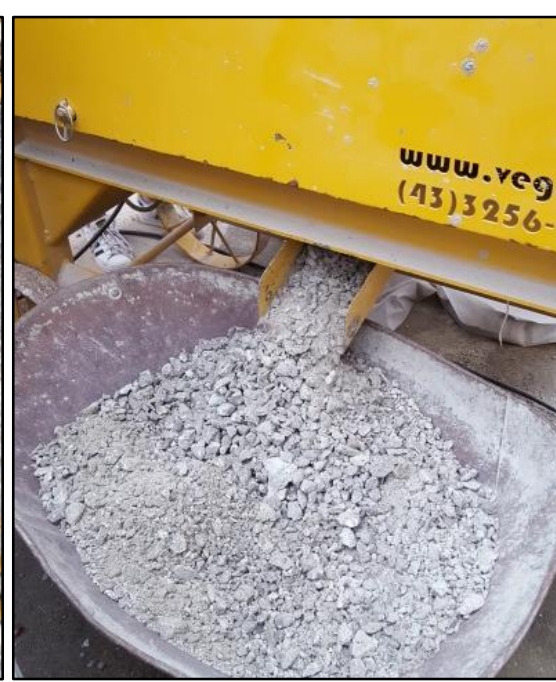

(e) coarse particles

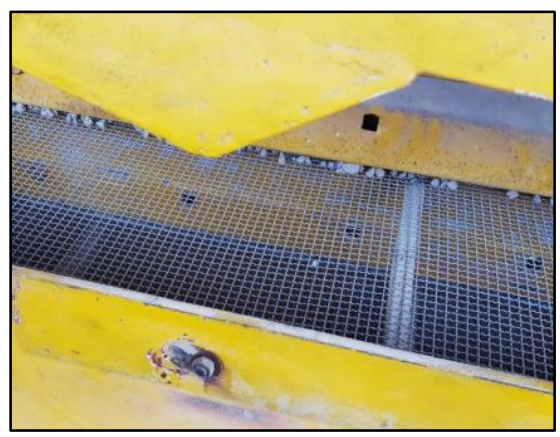

(h) sieving screen

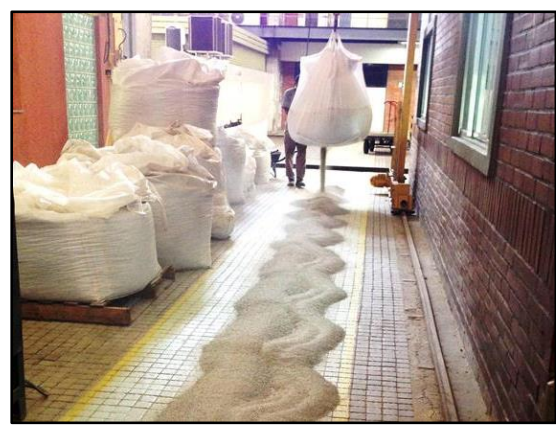

(k) RCAs sand pile

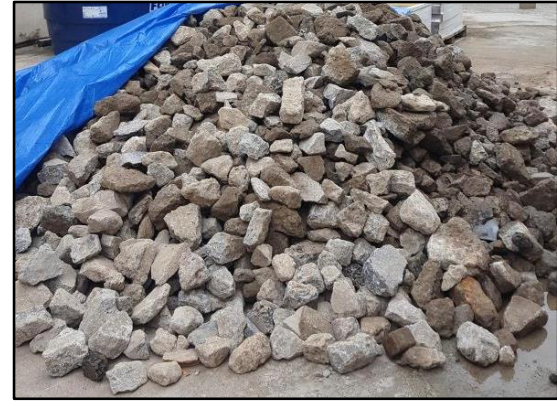

(c) D-waste

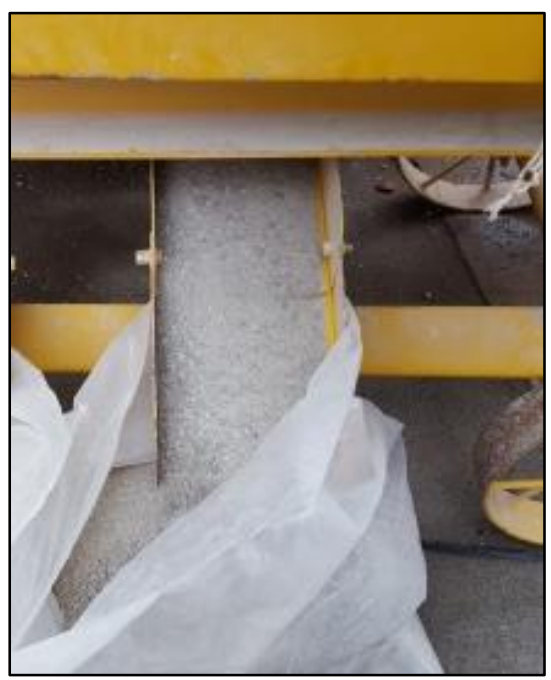

(f) fine particles

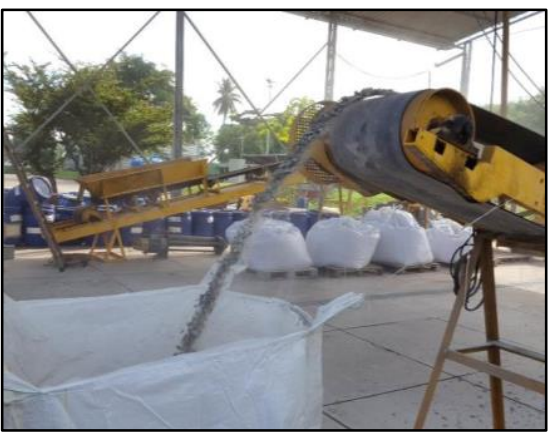

(i) classified RCAs

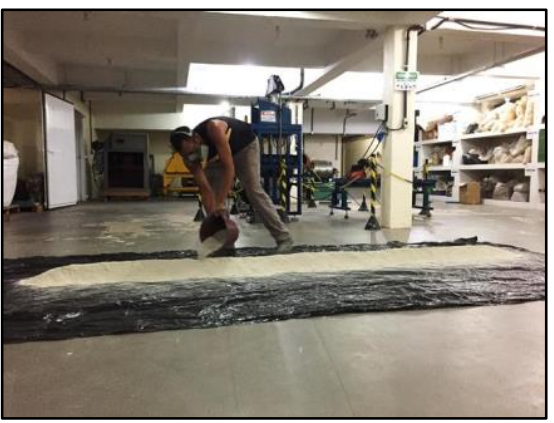

(l) RCAs powder pile

Fig. 1. The processing procedure: (a-c) visual aspect of the used concrete waste debris; $(d-f)$ crushing stage; $(g-i)$ industrial mechanical sieving stage; $(j-l)$ homogenization stage. 

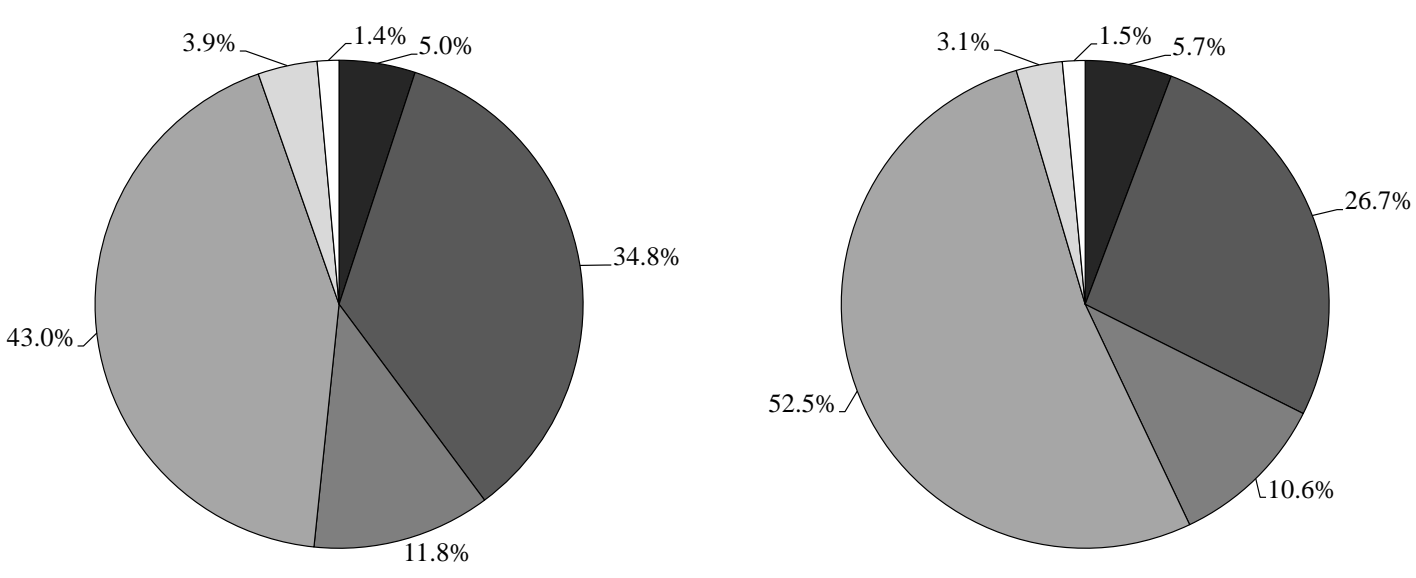

$\square>19 \mathrm{~mm} \quad \square \mathrm{C} 1 \quad \square \mathrm{C} 0 \quad \square$ Sand $\square$ Powder $\square$ Processing powder loss

(a) L-waste (b) $C$-waste

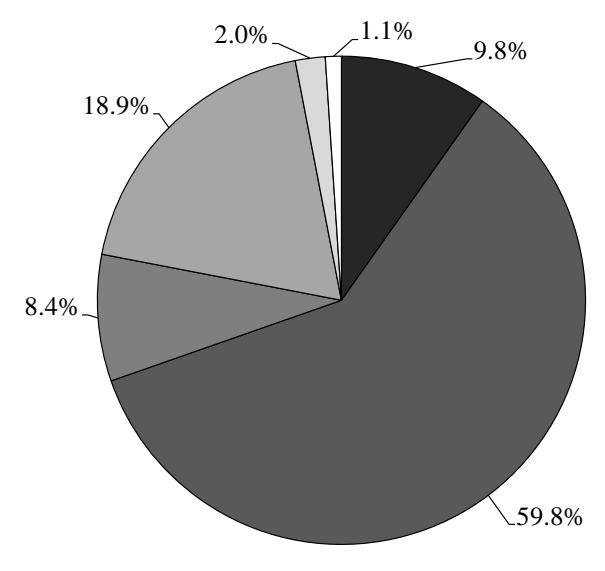

(c) D-waste

Fig. 2. Quantity of each granulometric fraction produced from each concrete waste 


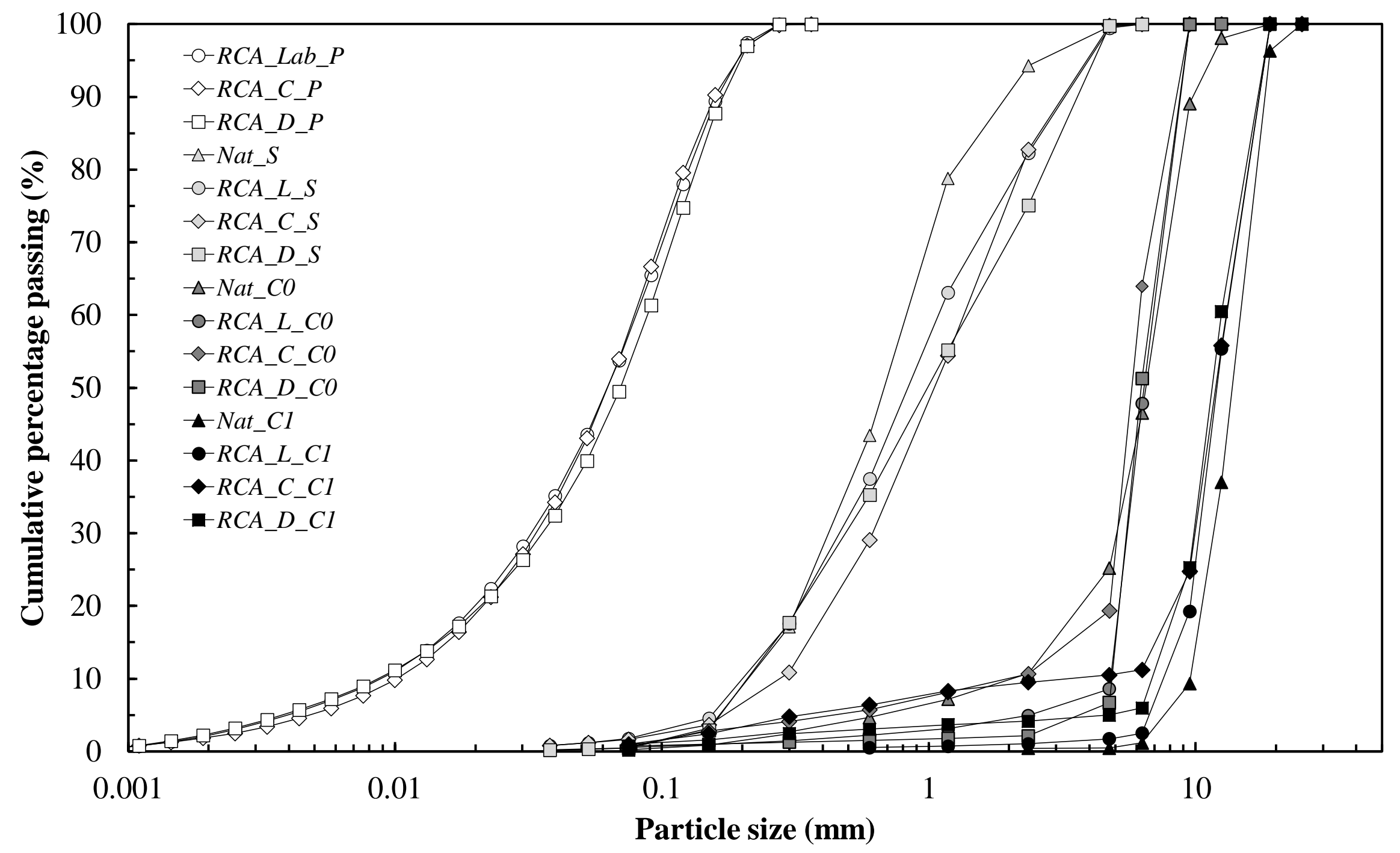

Fig. 3. Grain size distribution for coarse aggregates, sand and recycled powders 


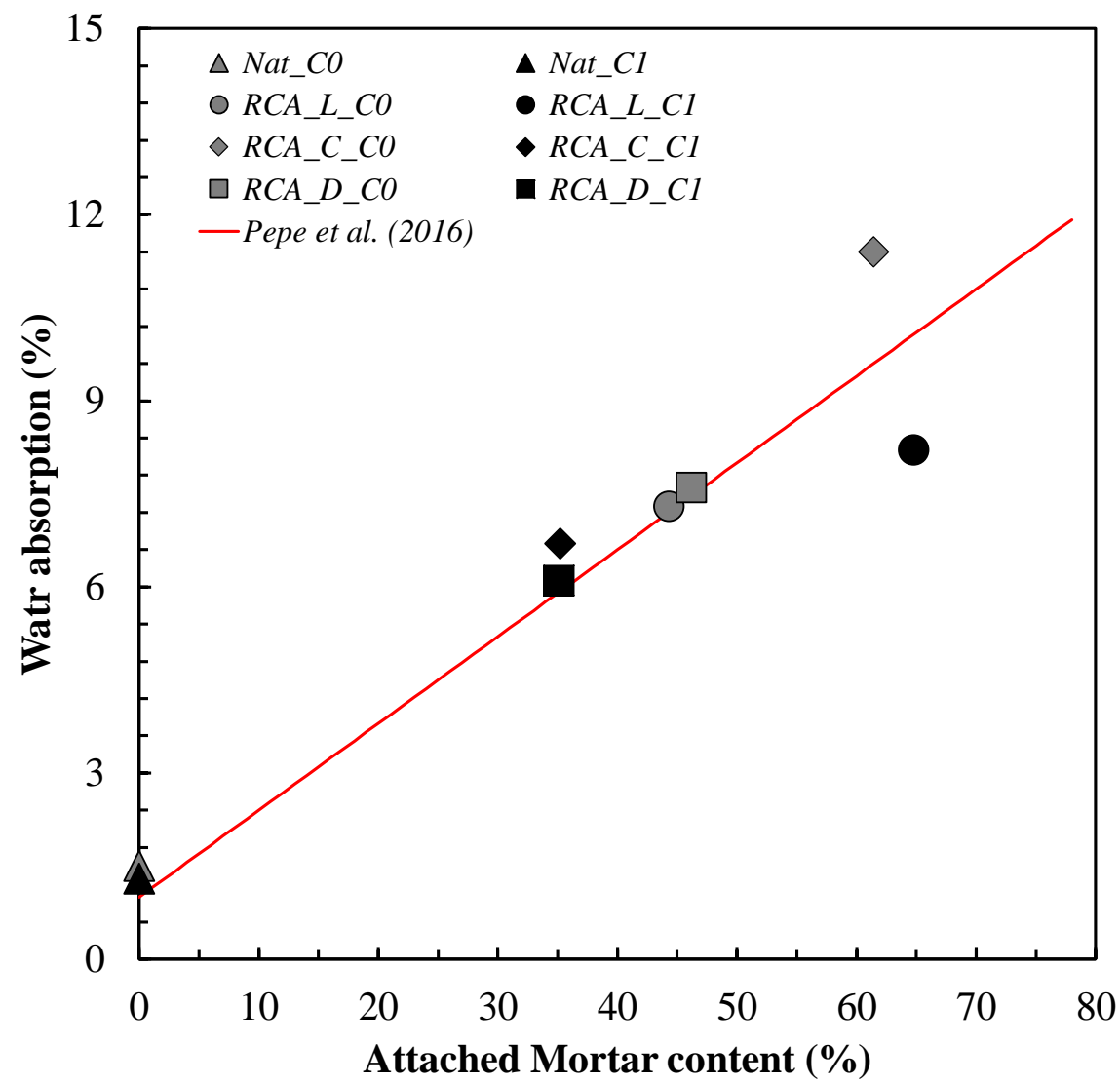

(a) Water absorption $x$ Attached Mortar

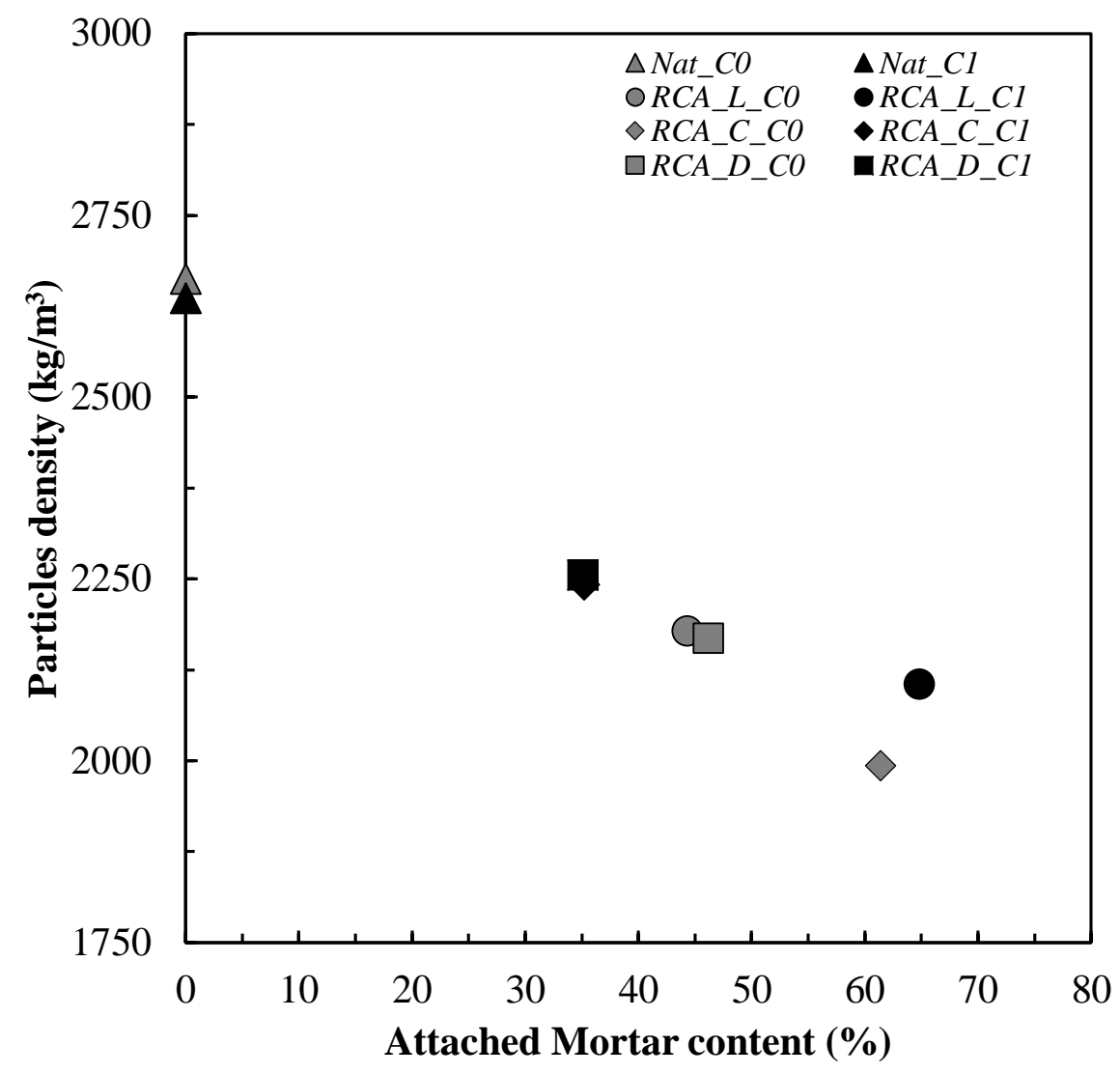

(b) Particles density $x$ Attached Mortar

Fig. 4. The influence of the AM content on the coarse RCAs properties 


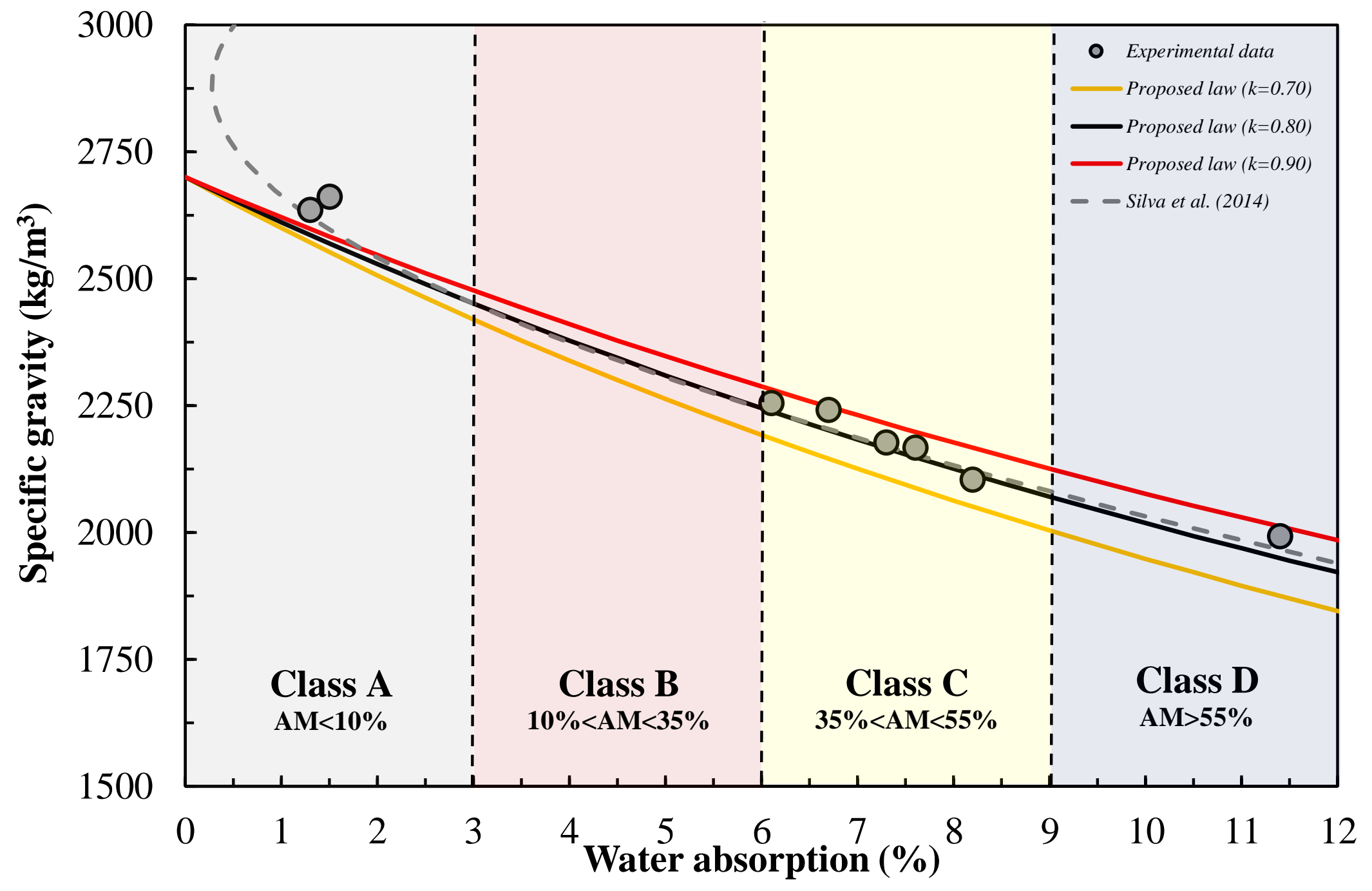

Fig. 5. Proposed classification for coarse RCAs 


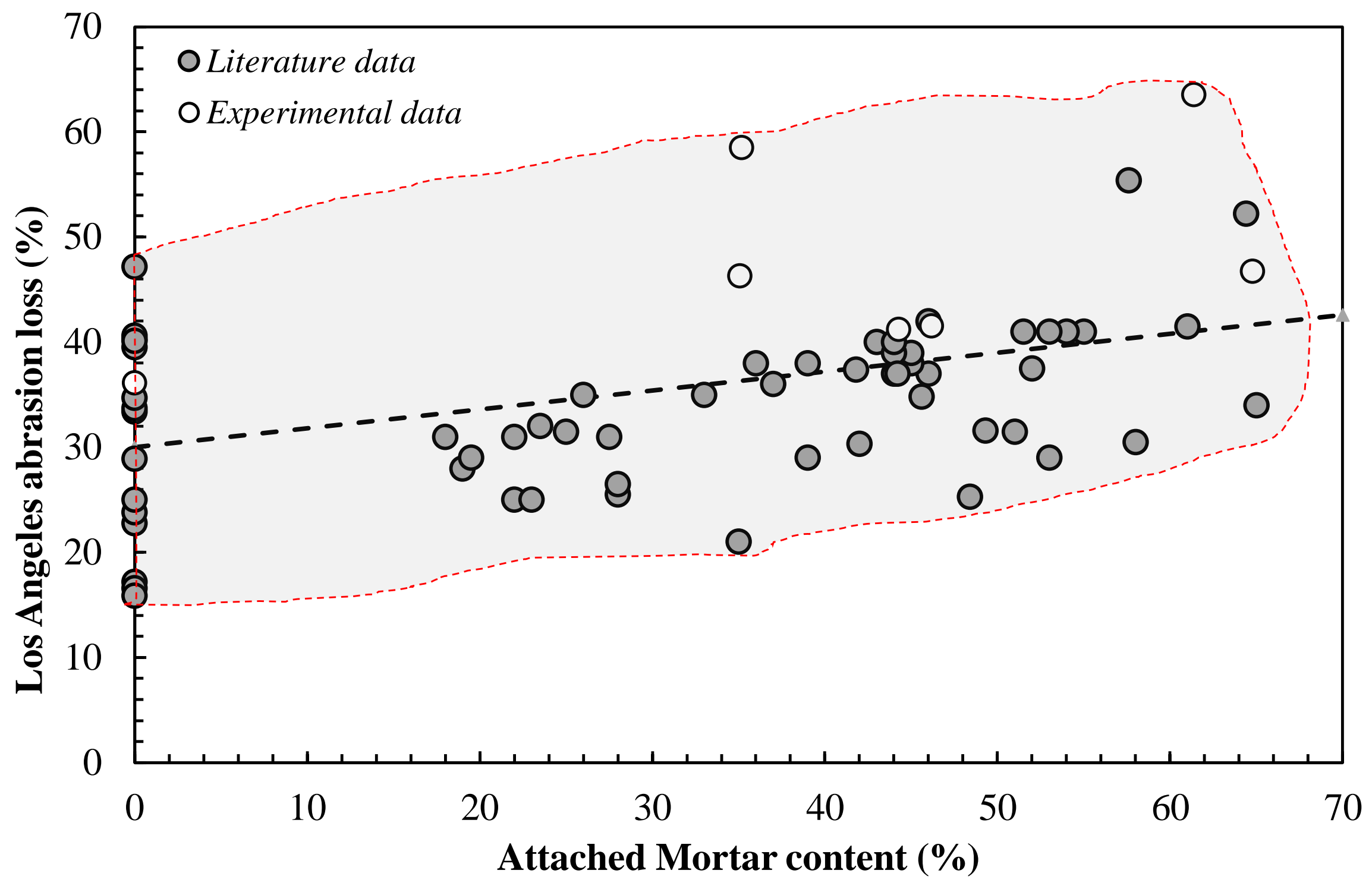

Fig. 6. Los Angeles abrasion loss for coarse RCAs 


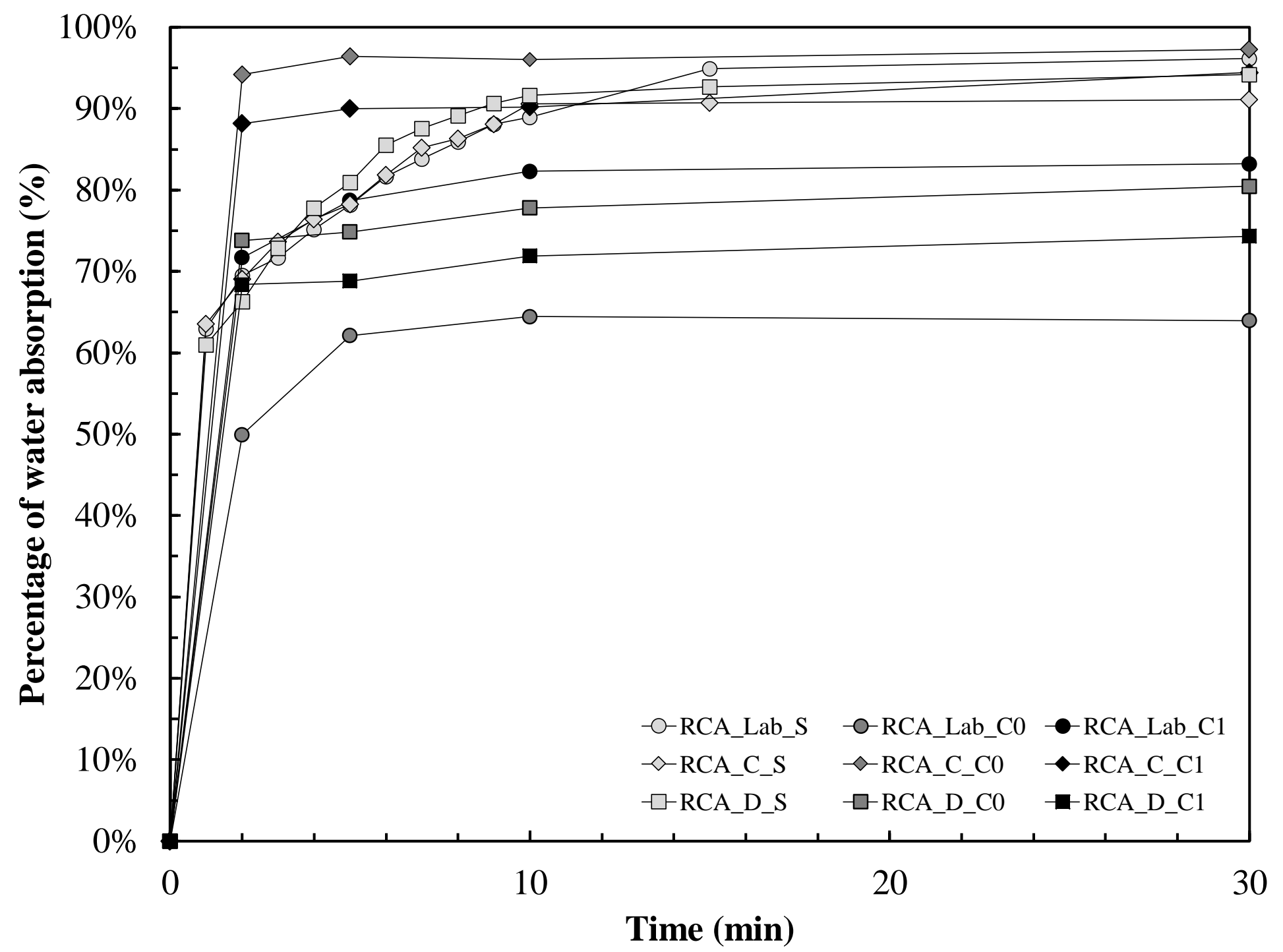

Fig. 7. Water absorption kinetic for the recycled aggregates 


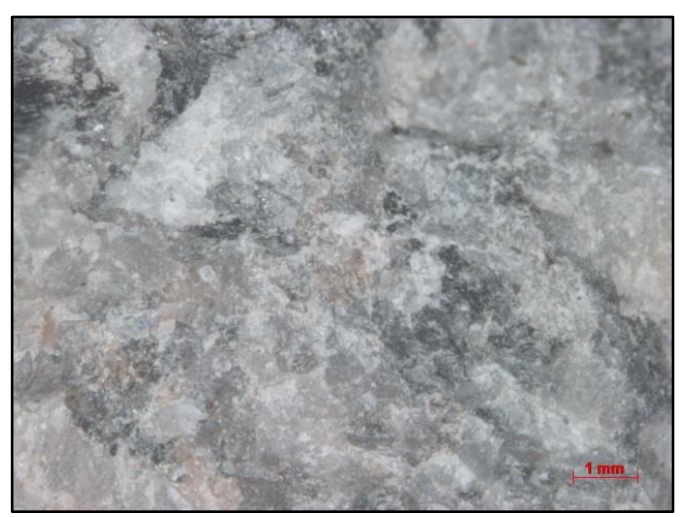

(a) Nat_Cl

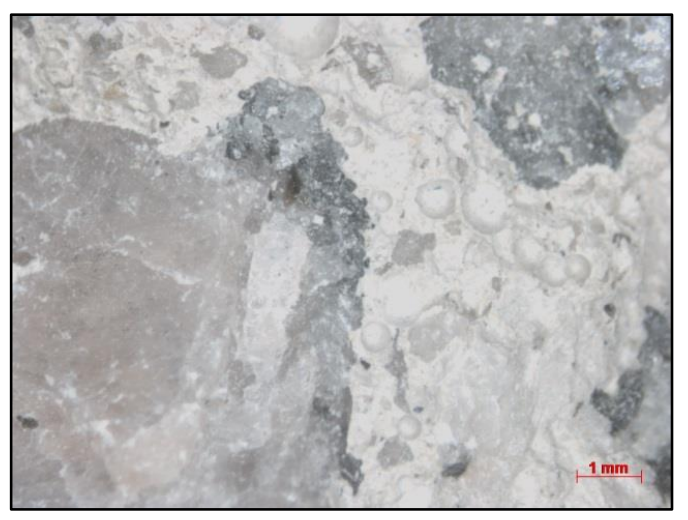

(c) $R C A \_L \_C l$

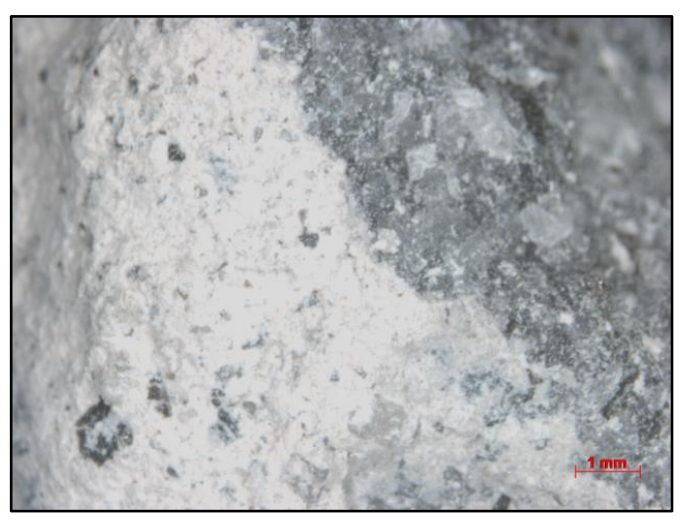

(e) $R C A \_C \_C l$

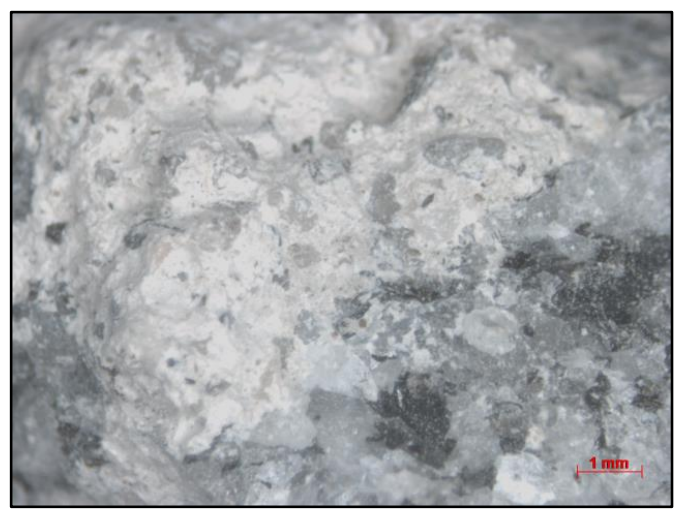

(g) RCA_D_Cl

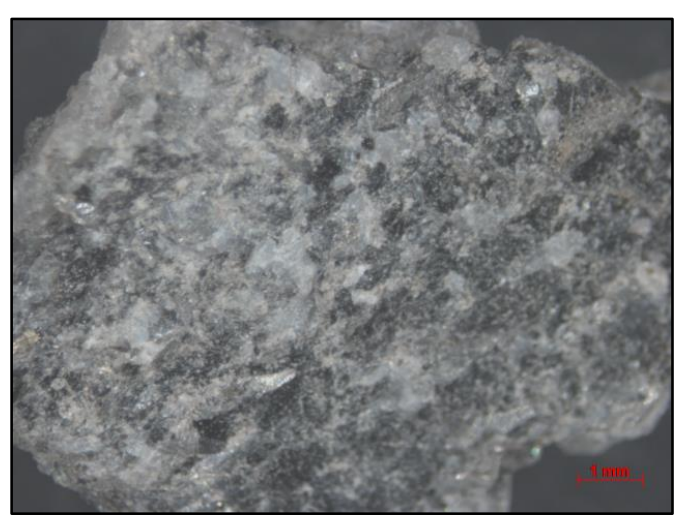

(b) Nat_CO

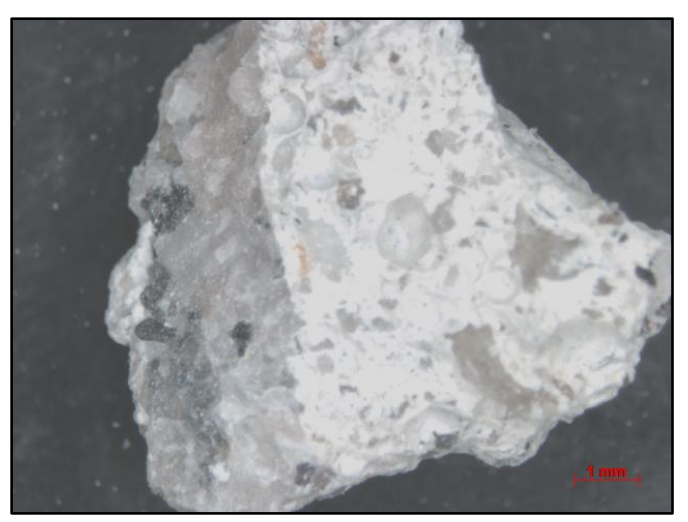

(d) $R C A \_L \_C O$

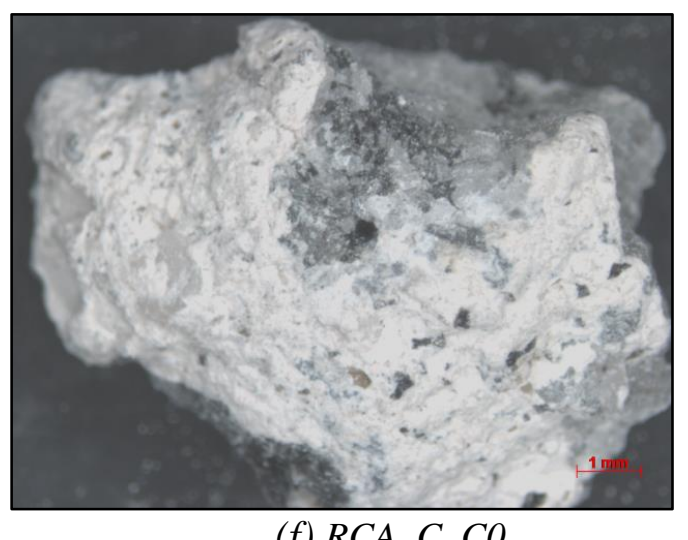

(f) $R C A \_C \_C O$

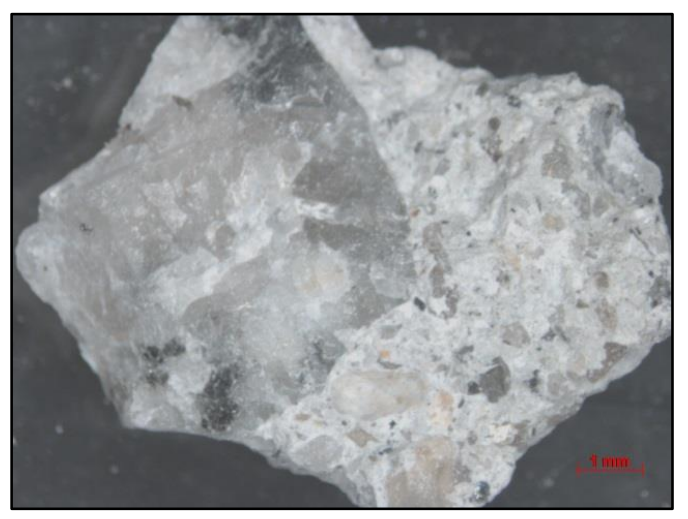

(h) $R C A \_D \_C O$

Fig. 8. Images for coarse particles 


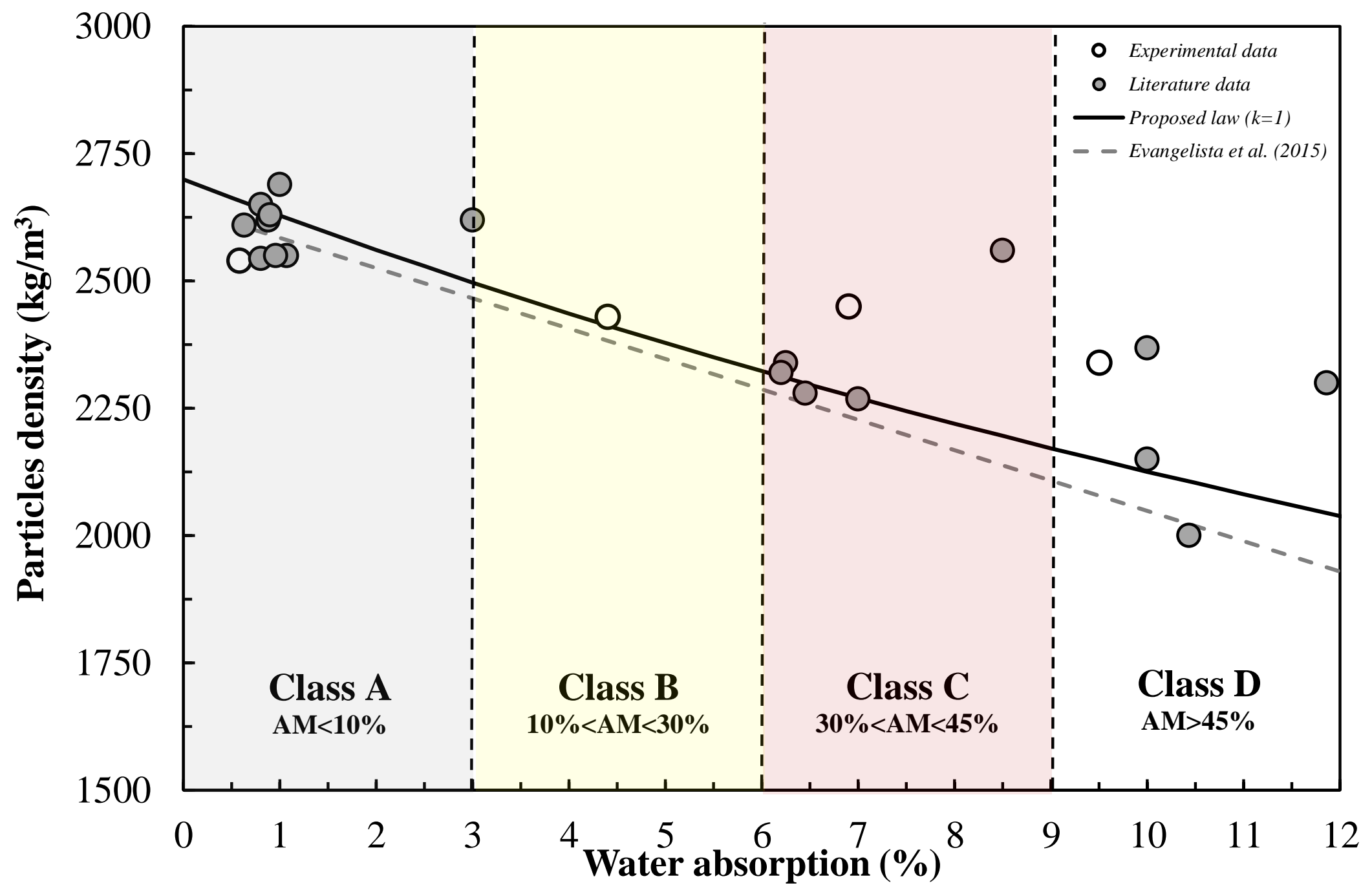

Fig. 9. Proposed classification for sand RCAs 


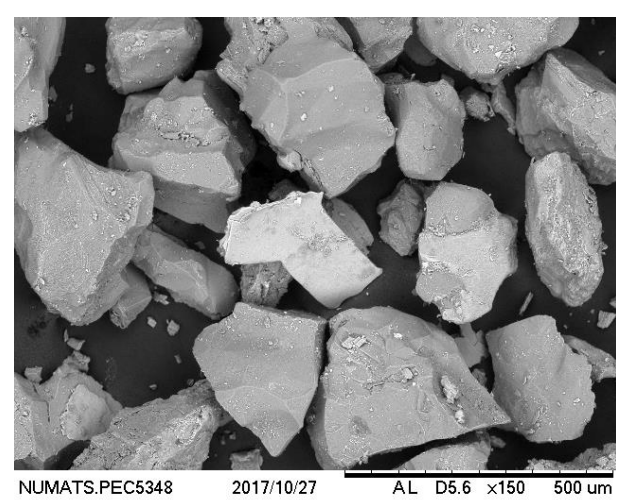

(a) Nat_S

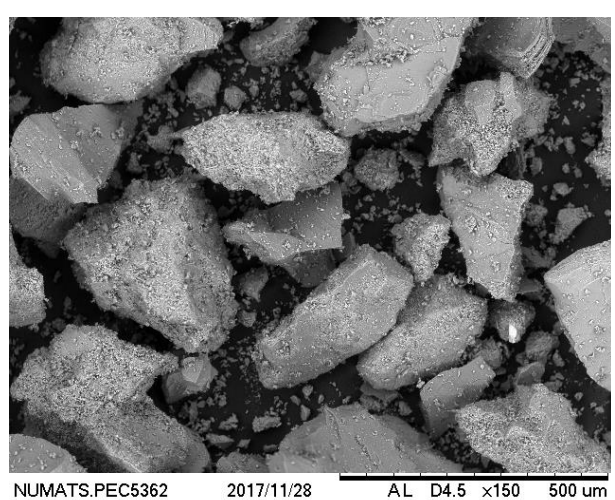

(b) $R C A \_L \_S$

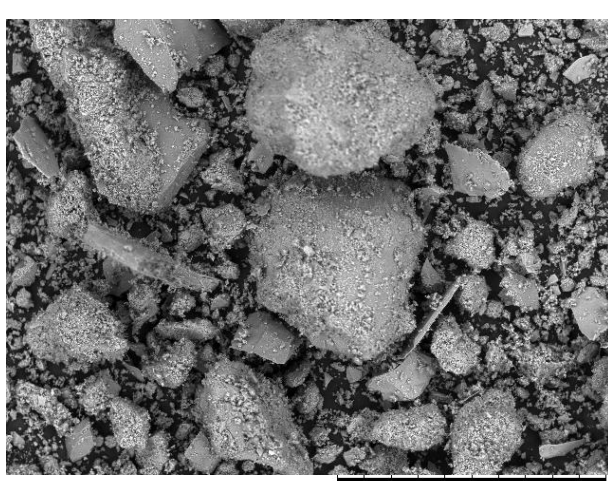

c) $R C A \_C \_S$

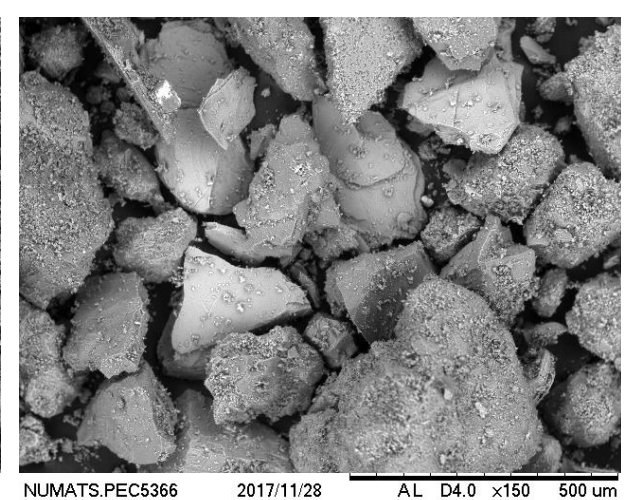

(d) $R C A \_D \_S$

Fig. 10. SEM images for sand class RCAs 


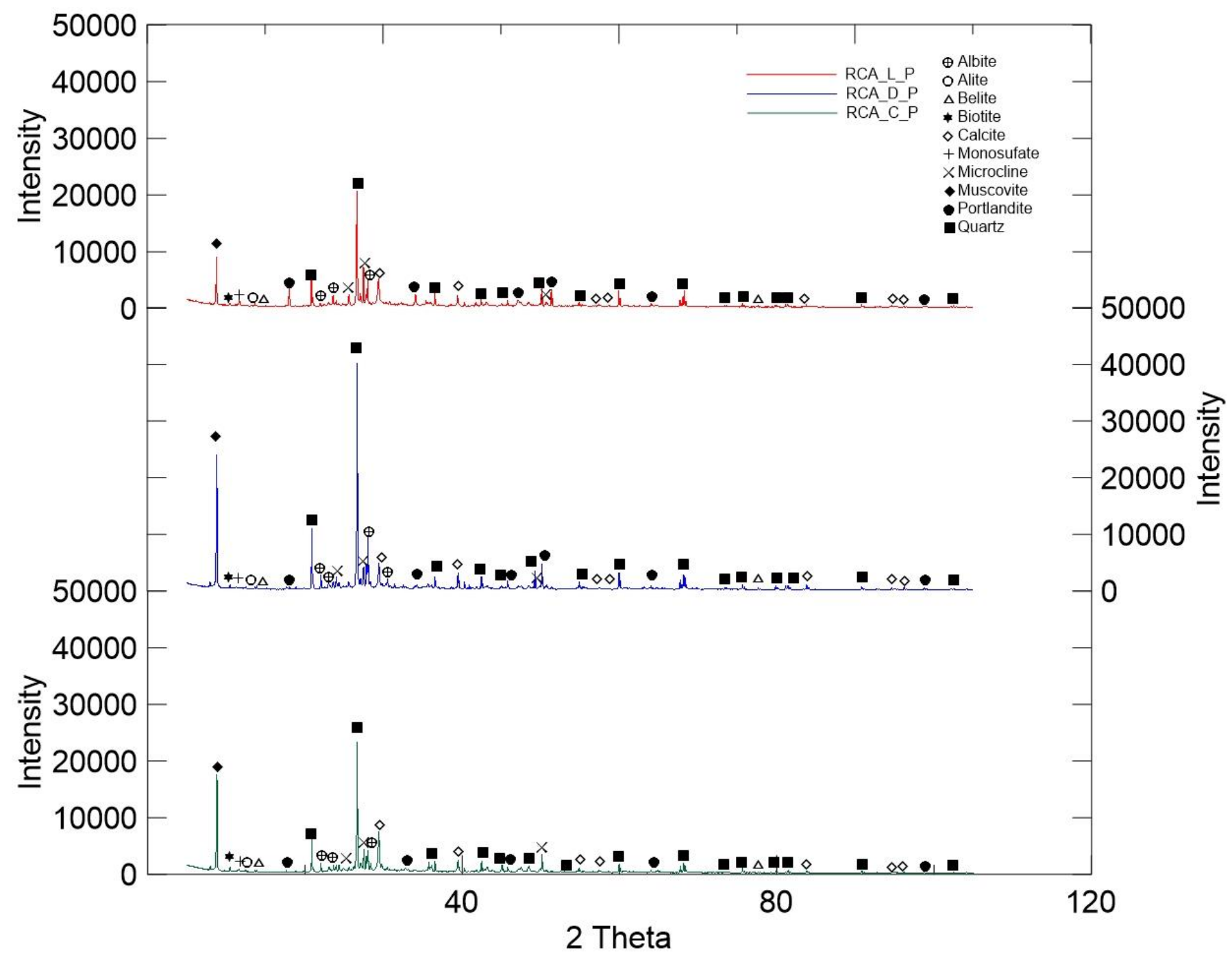

Fig. 11. XRD analysis for the used recycled powders 


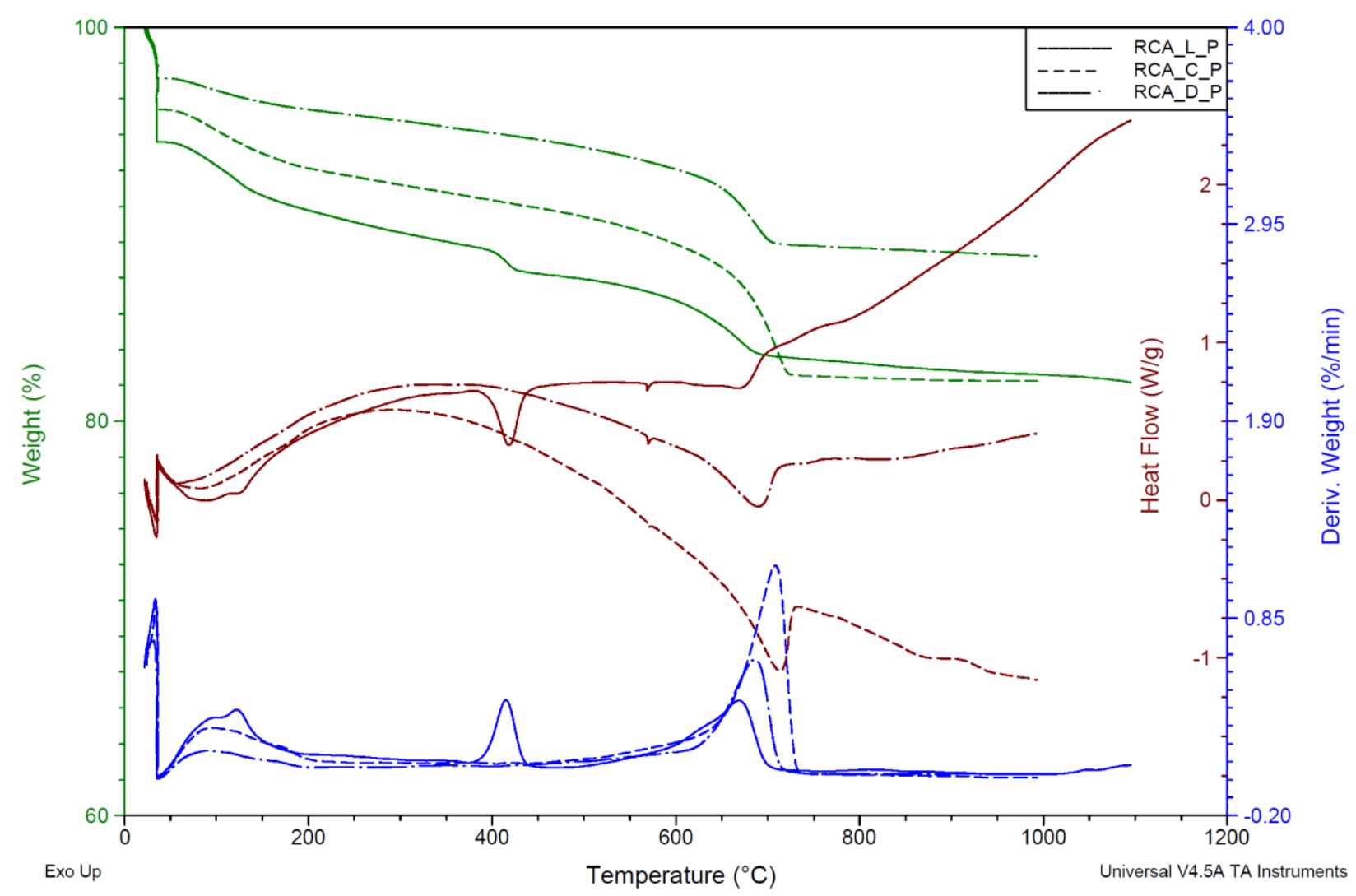

Fig. 12. TGA, DTG and DSC analysis performed on recycled powder 


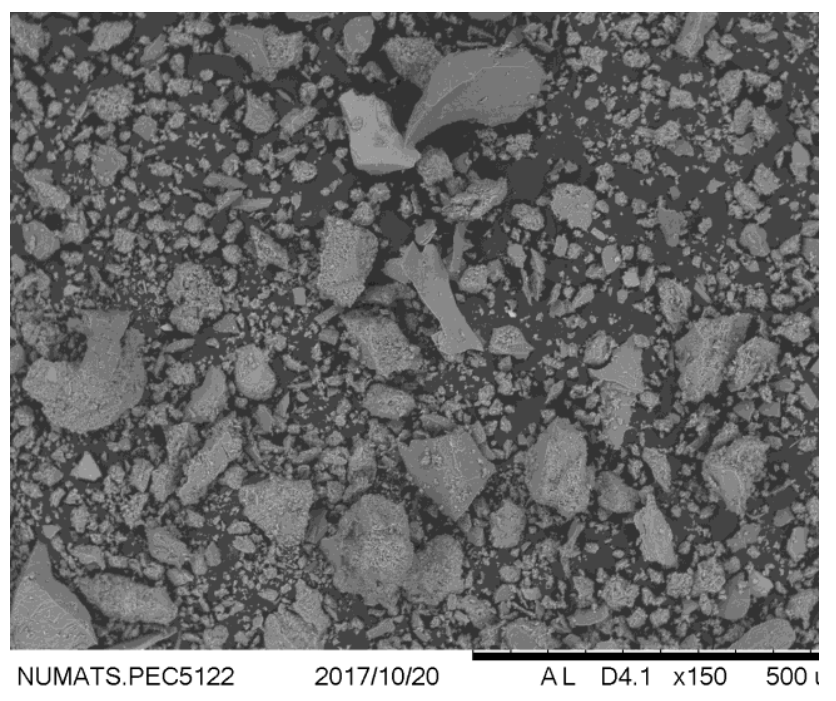

(a) $R C A \_L \_P$

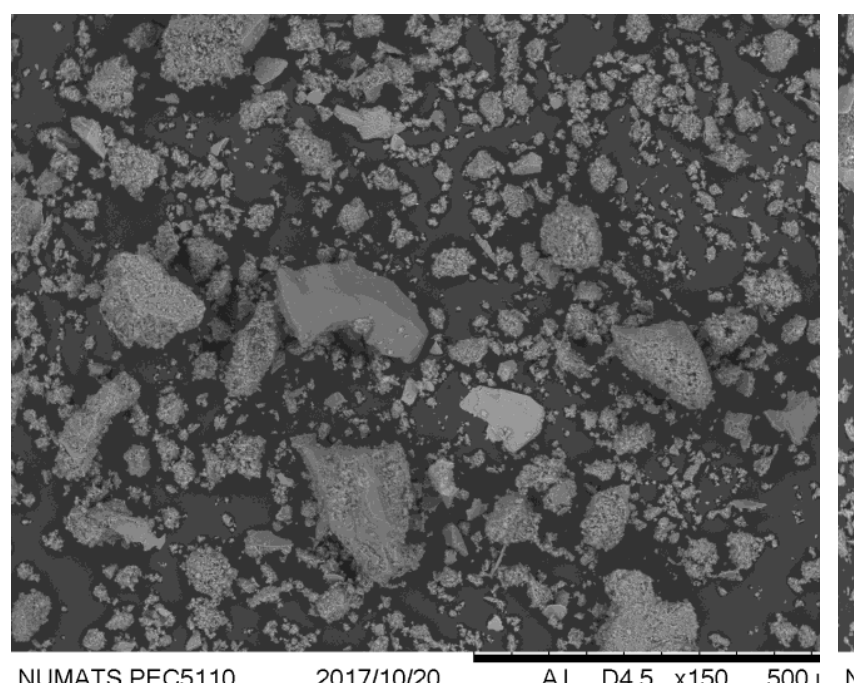

(b) $R C A \_C \_P$

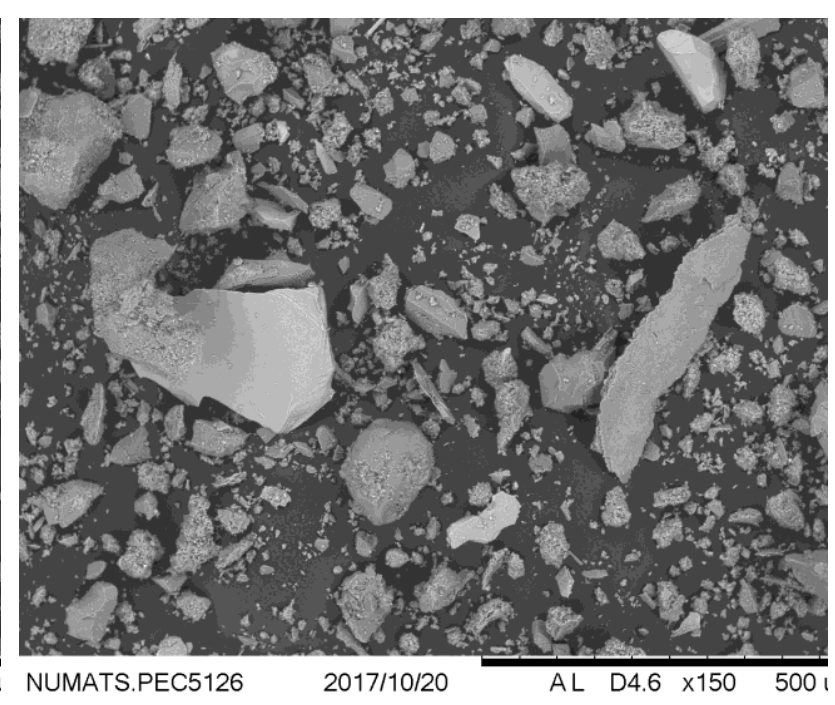

(c) $R C A \_D \_P$

Fig. 13. SEM images for recycled powders 
Table 1: Recycled and natural aggregates' classification

\begin{tabular}{|c|c|c|}
\hline Source & Granular class & Aggregates' nomenclature \\
\hline L-waste & $\begin{array}{c}\text { Coarse aggregate C1 } \\
\text { Coarse aggregate C0 } \\
\text { Sand } \\
\text { Powder } \\
\end{array}$ & $\begin{array}{c}R C A \_L \_C l \\
R C A \_L \_C O \\
R C A \_L \_S \\
R C A \_L \_P\end{array}$ \\
\hline C-waste & $\begin{array}{c}\text { Coarse aggregate } \mathrm{C} 1 \\
\text { Coarse aggregate C0 } \\
\text { Sand } \\
\text { Powder }\end{array}$ & $\begin{array}{l}R C A \_C \_C l \\
R C A \_C \_C O \\
R C A \_C \_S \\
R C A \_C \_P\end{array}$ \\
\hline D-waste & $\begin{array}{c}\text { Coarse aggregate } \mathrm{C} 1 \\
\text { Coarse aggregate C0 } \\
\text { Sand } \\
\text { Powder }\end{array}$ & $\begin{array}{l}R C A \_D \_C 1 \\
R C A \_D \_C O \\
R C A \_D \_S \\
R C A \_D \_P\end{array}$ \\
\hline Granite & $\begin{array}{l}\text { Coarse aggregate } \mathrm{C} 1 \\
\text { Coarse aggregate } \mathrm{C} 0\end{array}$ & $\begin{array}{l}\text { Nat_Cl } \\
\text { Nat_CO }\end{array}$ \\
\hline Quartz & Sand & Nat_S \\
\hline
\end{tabular}


Table 2: Properties of the coarse and fine aggregates

\begin{tabular}{|c|c|c|c|c|c|}
\hline RCA & $\begin{array}{l}\text { Specific gravity } \\
\qquad\left(\mathrm{kg} / \mathrm{m}^{3}\right)\end{array}$ & $\begin{array}{c}\text { Water } \\
\text { absorption } \\
(\%)\end{array}$ & $\begin{array}{c}\text { Attached } \\
\text { Paste/Mortar } \\
(\%)\end{array}$ & $\begin{array}{l}\text { Shape } \\
\text { index }\end{array}$ & $\begin{array}{c}\text { Abrasion } \\
\text { wear } \\
(\%)\end{array}$ \\
\hline Nat_S & 2540 & 0.6 & - & - & - \\
\hline$R C A \_L \_S$ & 2430 & 4.4 & 32.8 & - & - \\
\hline$R C A \_C \_S$ & 2340 & 9.5 & 37.1 & - & - \\
\hline$R C A \_D \_S$ & 2450 & 6.9 & 24.4 & - & - \\
\hline Nat_CO & 2662 & 1.5 & - & 3.1 & 39.5 \\
\hline$R C \bar{A} \_L \_C O$ & 2178 & 7.3 & 44.3 & 2.2 & 41.2 \\
\hline$R C A \_C \_C O$ & 1993 & 11.4 & 61.4 & 1.9 & 63.5 \\
\hline$R C A \_D \_C O$ & 2168 & 7.6 & 46.2 & 2.3 & 41.5 \\
\hline Nat_Cl & 2636 & 1.3 & - & 2.7 & 36.1 \\
\hline$R C A \_L \_C l$ & 2105 & 8.2 & 64.8 & 2.1 & 46.7 \\
\hline$R C A \_C \_C l$ & 2242 & 6.7 & 35.2 & 1.9 & 58.5 \\
\hline$R C A \_D \_C 1$ & 2255 & 6.1 & 35.1 & 2.3 & 46.3 \\
\hline
\end{tabular}


Table 3: Chemical composition for recycled powders

\begin{tabular}{cccc}
\hline & $\mathbf{L}$ & $\mathbf{C}$ & $\mathbf{D}$ \\
$(\boldsymbol{\%})$ & $(\boldsymbol{\%})$ & $(\boldsymbol{\%})$ \\
\hline $\mathrm{CaO}$ & 30.3 & 30.3 & 17.7 \\
$\mathrm{SiO}_{2}$ & 36.8 & 32.9 & 46.0 \\
$\mathrm{Al}_{2} \mathrm{O}_{3}$ & 8.8 & 10.2 & 12.6 \\
$\mathrm{SO}_{3}$ & 2.2 & 1.9 & 1.2 \\
$\mathrm{Fe}_{2} \mathrm{O}_{3}$ & 2.8 & 2.5 & 2.9 \\
$\mathrm{~K}_{2} \mathrm{O}$ & 2.3 & 1.2 & 2.4 \\
$\mathrm{MgO}$ & 0.92 & 3.1 & 2.4 \\
$\mathrm{Na}$ & 0.97 & 0.86 & 2.0 \\
$\mathrm{SrO}$ & 0.14 & 0.10 & $<0.1$ \\
$\mathrm{P}_{2} \mathrm{O}_{5}$ & 0.31 & 0.16 & 0.25 \\
$\mathrm{TiO}$ & 0.38 & 0.46 & 0.47 \\
$\mathrm{MnO}$ & $<0.1$ & 0.26 & 0.12 \\
$\mathrm{LOI}$ & 13.9 & 15.8 & 11.6 \\
\hline
\end{tabular}

